\title{
Current Trends in Explosive Detection Techniques
}

\author{
J. Sarah Caygilla, Frank Davis ${ }^{a}$ and Seamus P. J. Higson ${ }^{a},{ }^{*}$ \\ ${ }^{a}$ Cranfield Health, Vincent Building, Cranfield University, Bedfordshire, MK43 0AL, United \\ Kingdom
}

* Corresponding author. Tel: $+44(0)-1234-758516$. Fax: $+44(0)-1234-758380$. Email address: s.p.j.higson@cranfield.ac.uk (S.P.J. Higson)

\section{Abstract}

The detection of explosives and explosive-related compounds has become a heightened priority in recent years for homeland security and counter-terrorism applications. There has been a huge increase in research within this area - through both the development of new, innovative detection approaches and the improvement of existing techniques. Developments for miniaturisation, portability, field-ruggedisation and improvements in stand-off distances, selectivity and sensitivity have been necessary to develop and improve techniques. This review provides a consolidation of information relating to recent advances in explosive detection techniques without being limited to one specific research area or explosive type. The focus of this review will be towards advances in the last 5 years, with the reader being referred to earlier reviews where appropriate.

Keywords: Explosives detection; Explosive-related compound; Counter-terrorism; Review

\section{Contents}

Current Trends in Explosive Detection Techniques................................................................

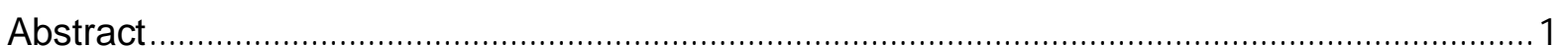

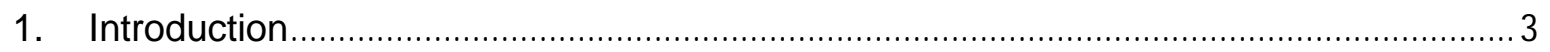

2. Spectroscopic approaches for the detection of explosives .............................................. 3

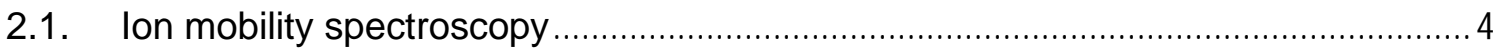

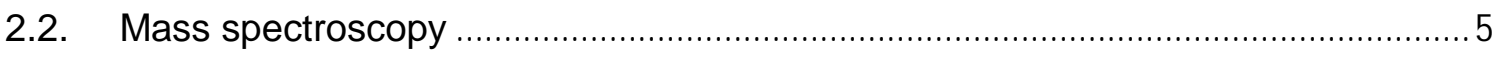

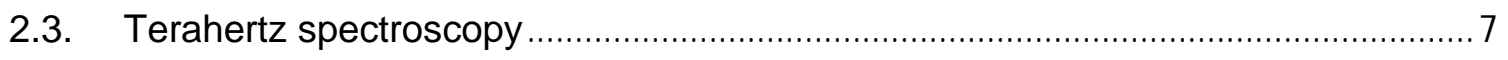

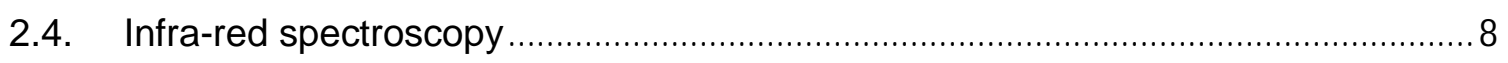

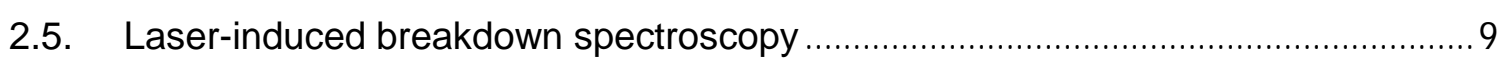

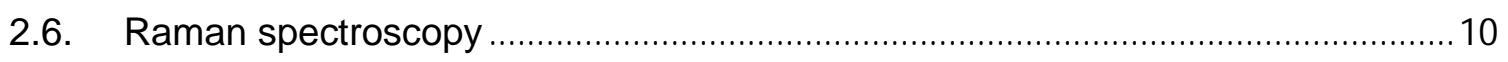

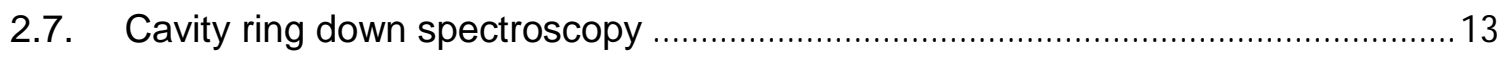




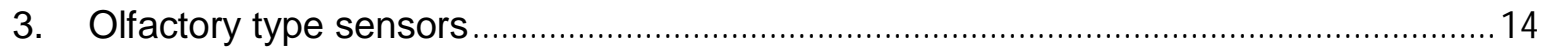

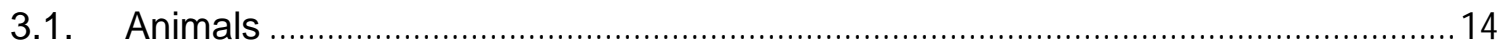

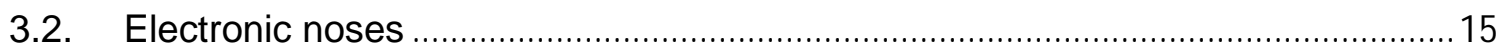

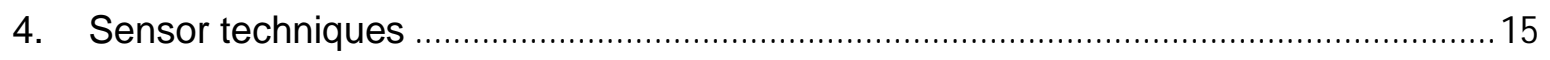

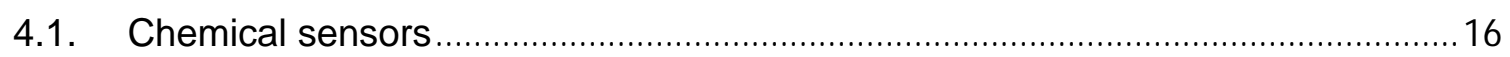

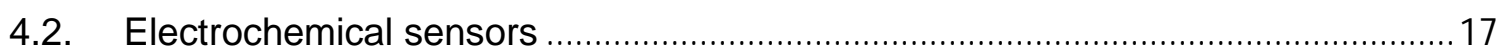

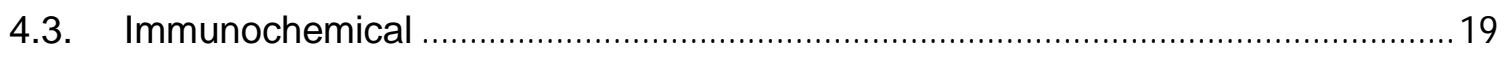

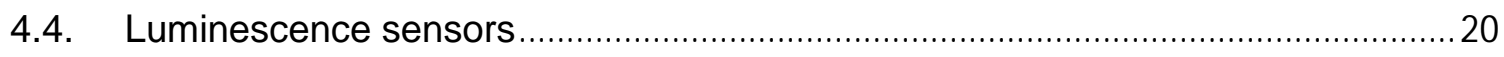

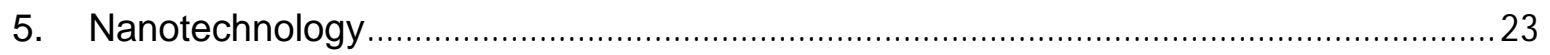

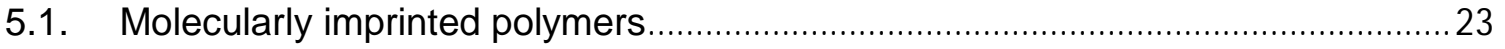

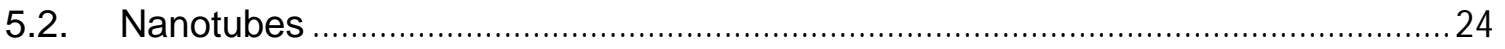

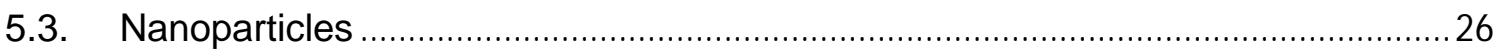

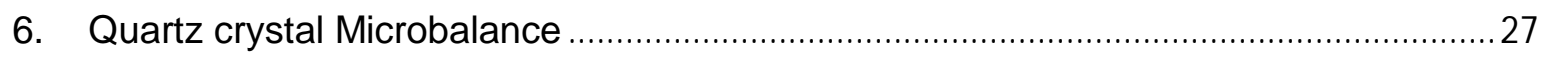

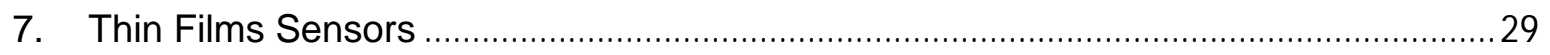

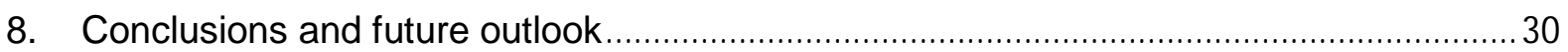

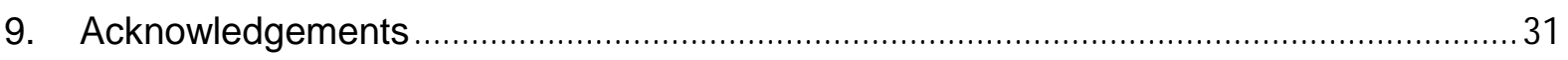

10. References .............................................................................. Error! Bookmarknot defined 


\section{Introduction}

Concerns relating to homeland security have given rise to increased research into explosive detection as well as further developments for existing analytical techniques to enable faster, more sensitive, less expensive and simpler determinations to facilitate the trace identification of explosives.

Traditional security measures at airports have included the use of metal detectors to identify weapons that may be concealed in conjunction with X-ray machines for viewing the contents of baggage. One major problem is that explosive substances are often not easily detectable using conventional approaches and in this context many terrorist groups have adapted to avoid the use of metallic objects. Approaches to detect volatile substances, such as ion mobility spectrometry in conjunction with swabbing, while in routine use - are largely only suitable for the screening of items of hand baggage.

For the detection of traces of explosive substances in the air, issues related to the low vapour pressures of many explosives are only exacerbated further when these explosives are wrapped or packaged to avoid detection. The increasing use of peroxide based explosives has led to much research into detection of this group of explosive substances, the issue being that many current chemical identification techniques are based on the nitrogen and carbon content of a substance for identification and this practice is not suitable for peroxide explosives.

This review primarily focuses on the detection of concealed explosives and their precursors / degradation products. Areas that are covered include trace, bulk and vapour detection techniques and those described for the stand-off detection of explosive substances. Peer reviewed papers from the last 5 years are presented as well as referring to other review papers of particular interest.

\section{Spectroscopic approaches for the detection of explosives}

The principle of mass spectroscopic methods is that samples are drawn from the air into a mass spectrometer where they are ionised, the resultant ions separated by electrical and magnetic fields according to mass charge ratio and detected and quantified. These methods display very high sensitivities and selectivities but are often expensive and require laboratory based equipment. Much current work is addressed to reducing size and cost of such equipment. 


\subsection{Ion mobility spectroscopy}

\subsubsection{Principle}

Ion mobility spectrometry (IMS) is one of the most widely used detection techniques in routine use due to its ability to characterise the sample both qualitatively and quantitatively as well as the very low detection limits that are often attainable. The reader is referred to a 2001 critical review of ion mobility spectrometry for the detection of explosives and explosive related compounds [1].

IMS characterises a sample through the mobility of ions within the gas-phase of the instrument whilst an electric field is applied (see figure 1). The sample vapours are ionised at atmospheric pressure before introduction into the drift tube. The drift times are related to the mass of the ions and by determining the mass/charge ratio, it is possible to identify components within the sample through comparison with known standards.

Most commercially available apparatus use ${ }^{63} \mathrm{Ni}$ or ${ }^{241} \mathrm{Am}$ [2] as the ionisation source. The radioactive nature of these ionisation sources, however, can cause concerns relating to safety and environmental impact. As such, there has been investigation into alternative sources for ionisation with a focus towards negative corona discharge approaches [2, 3]. Corona discharge as an ionisation source does have some associated complications, namely the variation of reactant ions produced, as compared to those gained with a ${ }^{63} \mathrm{Ni}$ source - as well as susceptibility to degradation of reactant ions and failure at the discharge point. Waltman et al., 2008, described a distributed plasma atmospheric pressure ionisation source that involved the application of a high-voltage alternating current across a dielectric to produce plasma within which the sample was ionised [4]. This technique was reported to be unaffected by tip erosion (of which corona discharge approaches can be prone) - and moreover requires less power than corona discharge sources.

Investigation into enabling the miniaturisation and portability of IMS apparatus for field deployment has increased over recent years. Tabrizchi and Ilbeigi, 2010, investigated a positive corona discharge technique using a curtain plate preventing the diffusion of $\mathrm{NO}_{\mathrm{x}}$ into the ionisation region so allowing analysis in air as opposed to nitrogen [5]. A shortening of the length of the drift tube and minimising the ionisation source would usually be associated with a corresponding decline in sensitivity, however, the use of a capacitive-trans impedance amplifier has been shown to offer resolution comparable with, and sensitivity exceeding, commercial bench top instruments [6]. An ion focussing aspiration condenser has been described where two parallel gas flows travel through a transverse electric field; the upper flow contains the ion stream which is then geometrically focussed until the ions are forced into the lower gas stream and onto the base electrode. The different ion species are 
separated by their mobility into separate beams and then detected. This apparatus typically uses less power, is less costly to manufacture, as well as being smaller than many commercial instruments - and for these reasons may be incorporated into a hand-held system [7].

Martin et al., 2007, described a micro-fabricated hotplate coated with a sorbent polymer as a technique to trap analytes of interest prior to analysis with IMS; this technique reportedly enhanced sensitivity by at least one order of magnitude [8]. A technique to decrease false positive results without any significant increase in analysis time has been described, using a short column packed with adsorbent packing material; this method enables pre-separation after ionisation of the sample furthermore offering the capacity to retain interference for longer, thus minimising their influence on the resulting spectra [9].

\subsection{Mass spectroscopy}

\subsubsection{Principle}

Mass spectrometry (MS) in various forms has been used successfully to detect explosives due to its specificity in identifying substances and the speed at which analyses are completed. Due to the size and expense of previous MS devices, this technique has not been widely used within some security oriented settings. Mass spectrometry separates and analyses the chemical composition of a substance according to its' mass-to-charge $(\mathrm{m} / \mathrm{e})$ ratio. Two methods by which this may be achieved include time separation and geometric separation based approaches. There are many forms of mass spectrometry including, for example: quadrupole, ion trap, time-of-flight (TOF) and tandem based techniques (MS/MS) [10].

The use of a mass spectrometer for security or forensic analyses would often involve the substance of interest either being within a complex sample matrix or absorbed upon a surface. Work has been undertaken towards improving the techniques for the introduction of samples into the mass spectrometer. The aim is not only the improvement of selectivity towards the material of interest, but also to remove the necessity for pre-concentration of samples before analysis. In addition to these factors, miniaturisation and lowering of unit cost have also been key research areas.

\subsubsection{Recent advances}

Ambient ionisation techniques have been investigated to address some of the issues mentioned above. Atmospheric pressure chemical ionisation (APCl) involves the ionisation of a sample and carrier gas within the gas phase using corona discharge. Song and Cooks, 
2006, further developed this technique by using the carrier gases acetonitrile and air to enable selective detection of nitroaromatic explosives through the formation of adducts that subsequently fragment in a predictable manner [11]. APCI has also been investigated using a reversed gas flow introduction into the source which improves the ionisation of nitro-compounds before introduction into the tandem mass spectrometer [12]. Samples were collected both using a swab and directly from the skin of a hand that had handled explosive material. Using this approach 2,4,6-trinitrotoluene (TNT) was detected at a concentration of $3 \mathrm{pg} \mathrm{L}^{-1}$. A single proton laser ionisation technique has been described as a rapid laser-based technique and enables explosive detection with little fragmentation, thus allowing easier identification of the parent ion [13]. Limits of detection for nitrobenzene and 2,4-dinitrotoluene (DNT) were reported to be $90-130 \mathrm{ng} \mathrm{L}^{-1}$ and $320 \mathrm{ng} \mathrm{L}^{-1}$ respectively. This technique was, however, only suitable for molecules with an ionisation energy above 10.49 $\mathrm{eV}$.

Desorption electrospray ionisation (DESI) enables analysis of the substance of interest in its ambient environment by bombarding it with a mist of electrically charged droplets so creating ions which are drawn into the mass spectrometer with a vacuum [14]. This technique has been employed in the swift and specific detection of explosives on skin [15] and within complex matrices such as diesel fuel and lubricants [16]. Direct analysis in real time (DART) is a technique similar to DESI in that a sample may be analysed in its ambient location without preparation; however, in DART an electrical potential is applied to a carrier gas and the resulting excited-state species desorb molecules from the sample which are introduced into the mass spectrometer $[14,17]$. This technique has been comprehensively tested on various surfaces including clothing, currency and concrete - as well as a wide variety of chemicals of interest $[18,19]$. A desorption corona beam ionisation source (DCBI) is also able to work under ambient conditions without preparation of the sample. This technique is similar to DART, however in this case a visible thin corona beam is generated which may be used to analyse a specific area of the sample surface or even to visualise the surface of the sample on a molecular level [20]. The reader is referred to several recent reviews that consider the advancements in ambient mass spectrometry in greater depth [21, 22].

The size of mass spectrometers have previously presented a drawback to their use, however, much work has been undertaken into the miniaturisation of components and addressing safety considerations to enable the development of field deployable instruments. A simulation was undertaken in 2004 to establish the worth of a miniaturised system involving an array of micrometer sized cylindrical ion traps that decreased the voltage necessary for operation and the resulting size of the device in its entirety [23]. The use of DESI with a portable mass spectrometer has demonstrated rapid detection of explosive 
compounds in situ from a variety of surfaces and, for example, with RDX (1,3,5-

Trinitro-1,3,5-triazacyclohexane) on paper, a LOD of less than $1 \mathrm{ng}$ was observed [24].

Sanders et al, 2010, demonstrated the detection of explosives on surfaces with a miniaturised system capable of detecting negatively charges ions. Samples of explosives were randomly applied to a large surface in $1 \mu \mathrm{g} \mathrm{cm}^{-2}$ quantities and a DESI mass spectrum corresponding to each of the explosive signals was observed [25]. Further investigation into the use of atmospheric pressure ionisation techniques with a cylindrical ion trap field-deployable mass spectrometer setup has demonstrated LODs of $1 \mathrm{ng}$ and $250 \mathrm{pg}$ for RDX and PETN (pentaerythritol tetranitrate) respectively [26]. A system integrating three methods has recently been described, employing thermal desorption, single photon ionisation and ion trap mass approaches. This system was tested using pure samples and those within a matrix. While significant fragmentation with those complex samples was found, the system was found to be free from false readings [27].

Coupled techniques such as gas chromatography- mass spectrometry (GCMS) have also been utilised. These systems combine the separation ability of gas chromatography with the sensitivity and specificity of a mass spectrometer. Since September 11th attacks, explosive detection devices have become incorporated into all US airports and many of these utilise GCMS A typical example is Thermo Scientific's EGIS Defender, licensed by the FAA for use at US airports (www.thermoscientific.com). This system couples high speed gas chromatography with ion-mobility mass spectrometry to give a system capable of detection of a range of explosives ( $\mathrm{C} 4$, Semtex, peroxides, TNT and nitrates) at nanogram levels in seconds. Other systems include the IONSCAN 500DT from Smiths Detection Technologies (www.smithsdetection.com) or General Electrics "puffer" system.

\subsection{Terahertz spectroscopy}

\subsubsection{Principle}

The field of terahertz $(\mathrm{THz})$ spectroscopy has been investigated many times over previous years as a technique for the detection of explosive vapour signatures [28-30]. There have been, however, drawbacks associated with this technology that have prevented development into a feasible system, and these include: the frame rate speed, a loss of attenuation as distance from sample increases, and, power requirements for the system [31]. Recently some of these issues have been addressed and the technology is further being considered as not only an explosive detection method, but also a way to detect weapons and other concealed objects within luggage and beneath clothing. Terahertz radiation lies in the far infra-red region - from 0.1 to $10 \mathrm{THz}$. In this range waves can penetrate through many non-polar dielectric materials, such as wood or leather, and the low photon energies 
are at a level one million times less than that of X-ray photons. Most explosives and explosive related compounds have spectral fingerprints within this range and, as many apparatus operate within the range $0.1-2.0 \mathrm{THz}$, this highlights $\mathrm{THz}$ radiation as a prospective sensor and imaging agent for the detection of concealed explosive substances.

\subsubsection{Recent advances}

Liu et al., 2006, described the detection and identification of both exposed and covered samples of RDX using diffusely reflected $\mathrm{THz}$ waves [32]. When the $\mathrm{THz}$ waves strike a smooth sample surface, the reflected beam has the same angle as the incident angle, this phenomena being known as specular Fresnal reflection. In reality, the sample surface is not usually smooth or aligned precisely within the $\mathrm{THz}$ beam and consequently the angle necessary for detection can be difficult to determine. As such, studying the diffuse Fresnel reflection (the reflection angle gained when a $\mathrm{THz}$ wave hits an uneven section of the surface) is more applicable to field-based analyses. Using this technique, Liu et al demonstrated the detection of RDX, exposed and covered by various materials, with a consistent fingerprint present at $0.82 \mathrm{THz}$.

Chen et al., 2007, investigated the absorption spectra of seventeen explosives and explosive related compounds (ERC) using THz spectroscopy [33]. Most of the substances examined exhibited characteristic absorption features in the 0.1-2.8 THz range. These results may be used to form a fingerprint database of explosives and ERCs. Through improvements in emitters and sensors, new spectral features have also been established for explosives within the frequency region of $3-6 \mathrm{THz}[29,30,34]$.

Work has been undertaken into the influence of so called 'confusion' materials such as, for example, food or toiletries, on the resulting spectra of any explosive compound also present [35]. It was established that while most of the confusion materials do not exhibit sharp spectral features in the terahertz region, substances containing sugar did have a spectral signature - although this does differ from the explosive substances within the test and so did not cause interference.

\subsection{Infra-red spectroscopy}

\subsubsection{Principle}

The principle of infra-red spectroscopic methods is that samples passed through an infra-red beam, certain groups adsorb at specific wavelengths allowing detection of many materials. Sensitivity and specificity can be issues and current work is attempting to address these challenges. 
Fourier transform infra-red (FTIR) spectroscopy is a technique largely used in to replace the more traditional dispersive instruments; this enables a considerable decrease in the time taken for sample analysis since it is capable of scanning all IR frequencies simultaneously rather than individually. An FTIR spectrum obtained was shown to allow identification of substances through its absorption at different wavelengths of light.

\subsubsection{Recent advances}

Primera-Pedrozo et al, 2009, reported a technique for the detection and quantification of high explosive residues on metallic surfaces using fibre optic coupled reflection/absorption infrared spectroscopy (RAIRS). When an infrared beam is directed at a smooth surface it passes through the sample and is reflected back through this coating again; this is known as specular reflectance and is the basis for the RAIRS technique. Coupling this technique with a Fourier transform probe, containing fibre optic cables that transmit in the mid-infrared range, enables analysis of samples in-situ rather than within the spectrometer sample chamber. Micro-RAIRS may also be used for topographical analysis of the substrate surface before sample examination. Low detection limits were reported of $160 \mathrm{ng} \mathrm{cm}^{-2}$ for TNT and Tetryl; $220 \mathrm{ng} \mathrm{cm}^{-2}$ for PETN and DNT; and $400 \mathrm{ng} \mathrm{cm}^{-2}$ for HMX (Octahydro-1,3,5,7tetranitro-1,3,5,7-tetrazocine) adsorbed on the metal surface [36].

The detection and identification of explosive particles in fingerprints has been described by Mou and Rabalais, 2009, using attenuated total reflection-Fourier transform infrared (ATR-FTIR) spectromicroscopy. Particles are first located within the ridges of the fingerprint using the ATR probe and then analysed with infrared radiation. The ATR-FTIR technique is classed as non destructive as the ridge patterns of the fingerprints remain the same and are therefore suitable for subsequent identification. The explosives particles present are able to be identified using a spectral library; however, in this work the library was not specific and did not contain the spectra of TNT and DNT - the analogue dinitrobenzene (DNB) was identified as closely matching those explosive compounds [37].

\subsection{Laser-induced breakdown spectroscopy}

\subsubsection{Priinciple}

Laser-induced breakdown spectroscopy (LIBS) uses a high intensity laser to vaporise the sample under investigation creating a plasma plume and the light subsequently emitted from this plasma enables characterisation of the sample. LIBS, as a detection technique, holds many advantages, especially in the field of explosives detection, some of which include: no need for sample preparation, the ability for real time results, apparatus that may be ruggedized and miniaturised for field work, a sensitive technique requiring only a small 
sample and the capacity for stand-off detection approach. For a more in-depth look at LIBS for explosive detection the reader is referred to Gottfried et al, 2009 [38].

\subsubsection{Challenges and advances}

Despite the obvious advantages of LIBS as a detection method, there are drawbacks associated with this technique. To enable use as a stand-off detection method, detection will usually need to be performed in the open air. The main constituents of many explosives are carbon, hydrogen, nitrogen and oxygen and it is the ratios of oxygen and nitrogen relative to carbon and hydrogen that form a distinguishing characteristic of many high explosive compounds. Inferences from oxygen and nitrogen in the atmosphere affect these ratios and, therefore, the characterisation of explosive compounds. This was illustrated by Lucena et al, 2010, in a comparison detection study of explosives in air and in helium [39]. De Lucia et al, 2007, proposed the use of a double pulse LIBS technique to diminish the effects of atmospheric interference. The double pulse increased the amount of excited atoms in the sample due to an increased plasma plume and it is believed that this also decreased the atmospheric gas density around the sample. This technique removed most of the atmospheric interference and aided discrimination between the explosive RDX and an organic material, diesel fuel [40].

To enable the detection of explosive materials at stand-off distances and in difficult to access areas Bohling et al, 2007, reported a LIBS system coupled to a probe like device which consisted of optical fibres, a focussing lens and a mechanical shutter system to protect the optics from any debris during use. The active fibre acts as an amplifier for the microchip laser and the passive optical fibre directs the laser pulses to the tip of the sensor. This system offers the possibility for combination with an automated device. Principle component analysis (PCA) and neural networking approaches were also reported in this paper to allow the identification of hidden objects with an accuracy above $80 \%$ and false identifications below $5 \%[41]$.

Dikmelik et al, 2008, proposed the use of femtosecond laser pulses to decrease the amount of fragmentation during the LIBS process. Nanosecond laser pulses are generally utilised although this tends to fragment a sample into its elemental constituents. When ultrafast excitation is employed, the fragmentation is less severe and emission is observed from $\mathrm{CN}$ and $\mathrm{C}_{2}$ molecules which may be used as a marker for, in this case, TNT [42].

\subsection{Raman spectroscopy}

\subsubsection{Principle}


Raman spectroscopy measures the vibrational transitions in a sample through the collection and analysis of scattered photons once the sample has undergone laser excitation.

Resulting spectra can offer a fingerprint of the item under analysis that can identify individual components of the sample. Due to the near instantaneous results and possible stand-off capacity, allowing samples to be analysed at some distance from the instrumentation [43], the potential of this technique for use as an explosives detection method has led to considerable work within this area. A review that described advances in the capacity of portable Raman instrumentation has also highlighted some of the issues relating to producing instrumentation for field deployable apparatus [44]. Sensitivity is an issue, much of this has been addressed by using techniques such as surface enhanced Raman spectroscopy which displays much higher sensitivity. Since much of the equipment used is still laboratory based, future trends indicate that much more portable instruments are required and are being developed. Use of fibre optic technology to allow remote sampling is also being investigated.

\subsubsection{Recent advances}

Pacheco-Londoño et al, 2009, reported the use of a continuous wave laser technique to increase the resulting signal to noise ratio and thus improve stand-off distances for explosive detection. Detection at distances of up to $7 \mathrm{~m}$ was described for the explosives TNT, DNT, RDX, TATP (triacetone triperoxide) and C4. The general-purpose plastic explosive Semtex containing RDX and PETN could not, however, be distinguished from the background interference due to the fluorescent nature of the explosive mixture. Limits of detection were achieved at $2 \mathrm{mg}$ for DNT and TNT; $3 \mathrm{mg}$ for RDX and C4 and $10 \mathrm{mg}$ for TATP at a distance of $7 \mathrm{~m}$ [45]. This study was not, however, conducted in a manner that transfers readily into a field-operable device since determinations were undertaken indoors and in the dark to minimise interferences.

A study into stand-off explosive detection in realistic field environments was undertaken by the Swedish Defence Research Agency. Measurements of various improvised explosive devices (IEDs) at stand-off distances of 20, 30 and $55 \mathrm{~m}$ were performed in varying weather conditions - from snow to sun and temperatures ranging from $+22{ }^{\circ} \mathrm{C}$ to $-8 \stackrel{\circ}{\circ}$. The instrumentation, including a $532 \mathrm{~nm}$ pulsed laser source, was kept inside a laboratory throughout the study and the beam directed outside onto an explosives approved test field. adjacent to the laboratory, thereby allowing the samples to be placed outdoors in an open environment. Bulk quantities of samples were satisfactorily identified through both regular glass bottles (green and brown) and PET (polyethylene terephthalate) containers and weather variations were found to have a minimal effect on measurements [46]. Issues that 
may arise include possible interfering fluorescence in the visible spectral region due to the container as well as how this system may cope with detection of trace amounts of the explosive substance.

The issue of interfering fluorescence may be addressed using a narrow gate width to exclude the majority of the interfering agents whilst still collecting the Raman signal relating to the sample. Fleger et al, 2009, propose such a technique - the interaction time for Raman scattering is less than $1 \mathrm{ps}$, however, luminescence scattering takes much longer between excitation and decay. As such, when a sample is interrogated with a short laser pulse, all Raman photons are generated almost instantaneously but the luminescence photons are generated over a longer time period. When the detection system has a narrow gate, all Raman photons will be collected with the minimum amount of luminescence. This allows a greater signal to noise ratio and enables detection of explosive substances with strong luminescent properties, such as Semtex [47].

The detection of explosive particles with backward coherent anti-Stokes Raman scattering (B-CARS) was studied by Portnov et al, 2010. Coherent anti-Stokes Raman scattering (CARS) involves three laser beams which interact with the sample and generate a new coherent optical signal at the anti-Stokes frequency. A spectrum with the same information as a spontaneous Raman spectrum is obtained though, with much higher sensitivity. B-CARS utilises the signal obtained from the diffuse reflections gained when a sample is interrogated using CARS. Using this technique the spectral fingerprint remains fundamentally the same as when processed with Raman, but the intensity is much greater with a more favourable signal to noise ratio. Stand-off distances were extrapolated to be as great as 180, 21 and $13 \mathrm{~m}$ for potassium nitrate, PETN and RDX respectively [48].

Confocal Raman microscopy enables the detection and identification of explosive substances and this approach can also provide information on physical properties such as the crystal structure, molecular orientation and possible interactions. Raman microscopy uses a focused laser beam within a microscope and operates in a confocal mode through the use of an aperture within the microscope - this enables depth recognition alongside the spectral profile usually gained with Raman spectroscopy.

Confocal Raman microscopy has been utilised for the detection and identification of explosive substances on the surface of human nail and from beneath a coating of nail varnish. It was discovered that although the nail itself produced spectral bands these did not inhibit identification of the explosives under examination, in this case PETN, TNT, AN (ammonium nitrate) and hexamethylenetetramine (HMTA), since interference could be excluded with careful focussing of the confocal beam. Coating the explosive and nail with 
nail varnish presented no additional problems for detection, with a two-dimensional Raman map gained for PETN and with no significant interference in the Raman spectra [49]. The same technique has been investigated for the detection of single particles of the explosives: PETN, AN and TNT [50]; as well as HMTA and pentaerythritol [51], on clothing. These studies looked at both natural and synthetic fibres, dyed and undyed, to imitate the in-situ detection of a person who may have handled explosive substances. Confocal Raman microscopy produced identifiable Raman fingerprints for each of the explosive compounds where each explosive particle was within the maximum dimensions of 5-10 $\mu \mathrm{m}$. Interference from the fibres, although present, did not fall within the Raman spectral profile of explosives tested. The main issue with this technique would appear to be visual identification of the explosive particles prior to testing.

\subsection{Cavity ring down spectroscopy}

\subsubsection{Principle}

In cavity ringdown spectroscopy (CRDS) a short pulse of light is injected into a resonant cavity which is surrounded by highly reflective mirrors. When sufficient radiation has built up within the cavity, the laser is turned off and the exponential decay of the intensity of the light is measured over time. The decay time for an empty cavity is then compared with one containing a substance of interest and a spectrum is obtained. The molecular absorbance, and therefore the concentration, may also be derived from the rate of decay. For a more in-depth overview of CRDS as a technique see Paldus and Kachanov, 2005, and Berden et al, $2000[52,53]$.

\subsubsection{Recent advances}

Ramos and Dagdigian, 2007, described a study into the use of ultra-violet CRDS as a means to improve on the low sensitivities related to infra-red CDRS. It was the case that UV-CRDS was able to detect the explosive related compounds 2,4-DNT and 2,6-DNT at concentrations 100 times less than their room temperature vapour pressures. The issue, however, was that this technique was unable to decisively identify specific samples due to its poor selectivity in the $240-260 \mathrm{~nm}$ spectral range [54]. This seems to be in opposition to IR-CRDS which has distinct spectral features but much lower sensitivity. There was also an issue with atmospheric interferences, especially ozone. It was suggested, however, that coupling this device with a less sensitive but more selective technique could overcome these problems. An increase in laser pulse energies may also lower the noise related to the photon decay; however, applying this technique to improve sensitivity also has the capacity to distort the decay profile through pre-dissociation of the compound leading to issues of identification [55]. 
Snels et al, 2010, reported a feasibility study involving the use of flash heater in a CRD cell to evaporate solid explosive samples prior to detection in the near infrared (see figure 2).

This technique aimed to address issues previously described in the literature such as poor selectivity in the UV region and the inability to record a full CRD spectrum in short time periods when recorded in the mid-infrared range. The discrimination between three similar compounds, 2,4-DNT, 2,6-DNT and TNT, was possible with the use of PCA and detection limits were reported at around $75 \mathrm{ng}$. Suggestions to improve this technique include the use of higher reflectivity mirrors and alternative heating geometry [56]. This technique was performed in ambient atmosphere with little interference, however, measurements at room temperatures were not possible and neither were investigations into explosive vapours in air.

\section{Olfactory type sensors}

Two types of olfactory sensor can be thought to exist, natural and artificial. Dogs have long been used to detect explosives and other species are being investigated, however the issues facing these methods are time and cost of training animals and lack of quantitative information. Electronic noses are being developed but as yet do not have the specificity and reliability for field use. Improving the performance of these artificial noses is necessary before they will be suitable for field work.

\subsection{Animals}

Dogs have long been known to have a highly developed sense of smell and this has been exploited for the detection of explosives since World War II [57]. The use of sniffer dogs for the detection of volatile explosive vapours is still widespread due to their fast, directional and real-time capabilities. Some studies have been undertaken into the reliability of canines for detection of explosives as there can be inconsistency between different dogs and the same dogs at different times [58]. Other animals have also been studied to establish any suitability for vapour detection. Rats have a sensitive and discriminating olfactory system and have been shown to correctly discriminate between odours and alert when explosives are present using a remote monitoring technique [59]. Insects, such as Drosophila melanogaster, have also been investigated due to the capability they have to detect a large range of odours and the simple olfactory system they possess. Incorporation of insect olfactory receptor neurons into a biosensor array has been reported by Marshall et al, 2010, with some success towards detecting illicit substances [60]. A comprehensive discussion into neural processing and olfactory research has been produced by Glatz and Bailey-Hill, 2010 [61].

There has been work attempting to establish the method by which an animal is able to detect an explosive target, whether it is through establishing an olfactory search image [62] or if the 
olfactory ability is predetermined by the polymorphisms in olfactory receptor genes - in this case, of the canine [63]. Detection of TNT and RDX has been demonstrated with olfactory sensory neurons obtained from rats and pigs [64], suggesting that explosive compounds do indeed interact with and activate olfactory receptors.

\subsection{Electronic noses}

A comprehensive review describing fluid dynamic sampling and its potential relationship to artificial olfactory devices has been published [44] which includes a broad discussion of contemporary artificial sampling techniques as well as suggestions for future research areas.

Artificial olfactory type sensors "electronic noses" have also been applied towards the detection of explosives [65]. Electronic noses usually consist of an array of chemical sensors which interact with a vapour in different ways and to different extents, combined with a pattern recognition system such as an artificial neural network. The basic principle is that each sensor will give a different response depending on the nature and concentration of vapour present and the pattern recognition process will allow determination of the analyte. $A$ detailed description of electronic noses and their application to explosive detection is beyond the scope of this chapter but has been reviewed elsewhere [45].

The chemical sensing elements can be electronic, piezoelectric or optical in nature and be organic or inorganic. Typical examples could include arrays of fluorescent polymers which can be quenched by interaction with a vapour. Only those polymers that interact are quenched. Fluorimetric arrays can also be used which consists of layers of multiple silica or polymer beads incorporating fluorescent dyes which are quenched by explosive vapours [66]. These can be photographed by a CCD camera and used determine a variety of organic vapours including nitroaromatic comounds. Polymer/carbon black composite films which change their conductivity upon exposure to vapours can also be used, although each film is not specific in itself, the overall changes in the array can be used to determine the presence of analytes [67]. Other workers have utilised gold nanoparticle arrays and measured the change in their conductivity upon exposure to vapours [68]. Piezoelectric type devices have been used such as surface acoustic wave devices or microcantilever sensors [65].

\section{Sensor techniques}

One technique that can potentially address many of the issues required for reproducible detection of explosives is that of sensors which could be low cost, portable and specific. The principle of sensors is that they contain an immobilised active species, such as an enzyme, which can selectively recognise the explosive required. A transduction step which can be optical, electrochemicalo or some other technique is then required to convert the recognition 
event into a measurable change, such as the production of electrons which can be measured at an electrode. However sensitivity is an issue, many sensors cannot simply detect the low levels of explosive vapours required. The future trends for this field are attempts to improve sensitivity, reliability and reproducibility

\subsection{Chemical sensors}

The principle of chemical sensors is a simple one, to have a chemical which undergoes a selective chemical reaction with an explosive vapour, leading to an observable product such as a change in colour or conductivity. TNT is a system containing an aromatic ring substituted with electron withdrawing nitro groups. This means it will form charge transfer complexes with systems that can donate electrons. For example reacting TNT with bases leads to strong visible colour changes [69]. These types of systems have been commercially exploited, for instance in the EXPRAY and DROPEX systems, where suspected surfaces (clothing, packages etc) are wiped with a special test paper and then the paper sprayed with proprietary aerosols. Colour changes are indicative of the presence of trace amounts of explosive. There are several aerosols and from the colour developed in response to each aerosol it is possible to determine the presence and identity of explosive. Targets include TNT, DNT, plastic explosive and nitrates.

A suitable base for reaction with TNT is the organic amino group and this has been used to modify silicon nanowires to give electrochemical sensors which can detect TNT in water down to sub-femto molar concentrations [70]. Other workers modified silica nanoparticles with amine groups and fluorescent dyes, the amine groups bound TNT which then quenched the fluorescence of the dyes, allowing detection of the explosive at levels of $1 \mathrm{nmol}^{-1}$ TNT in solution and several ppb of TNT vapour in air [71].

Other chemical sensors include ones based on conductive polymers. Recent examples include an electrochemical sensor based on polyaniline deposited on an electrode as a nanofibrous composite with a polypeptide. Amino groups within the polypeptide form complexes with electron-deficient species such as TNT, this immobilises the TNT in close proximity to the conducting polymer, allowing its determination in solution by adsorptive stripping voltammetry [72]. Other workers used a composite of polyaniline and carbon nanotubes for the detection of nitroaromatic vapours including TNT. The amine group of polyaniline forms a charge transfer complex with TNT, leading to an increase in the electrical resistance of the polymer [73]. Another conducting polymer used within a vapour sensor is poly(3,4-dioxyethylene thiophene) (PEDOT) which could be deposited to form a conductive nanowire between two gold electrodes. Coating this electrical junction with an ionic liquid allowed the system to adsorb TNT vapour from the air and then the electrochemical 
reductions of TNT as well as the conductance change of the polymer nanojunction caused from the reduction product could be simultaneously measured. This sensor is capable of detecting within a few minutes parts-per-trillion level TNT in the presence of various interferents [74].

\subsection{Electrochemical sensors}

\subsubsection{Principle}

Electrochemical sensors can be categorised into potentiometric (measurement of potential difference/voltage); amperometric (measurement of current) and conductimetric (measurement of conductivity) based devices according to the transduction approach adopted [75]. These types of sensor are fast, inexpensive with high sensitivity and a viable option for miniaturisation [76]. Electrochemical detection techniques can respond to redox substances; the electrical output results from a flow in electrons or ions caused by the chemical reaction that takes place at the surface of the electrode. Due to this, the redox properties of nitroaromatic explosive substances ideally lend themselves to electrochemical detection. The detection of peroxide based explosives is more complex due to the fact they do not fluoresce, have minimal UV absorption and a lack of nitro groups - all necessary parameters upon which traditional detection techniques are based [77]. Electrochemical sensors in this context offer an opportunity to detect peroxide based explosives that would otherwise prove problematic.

\subsubsection{Recent advances}

Square-wave voltammetry (SWV) is an often described technique for field-based operations due to the speed of scan rates, the sensitivity and the compact, low power instrumentation available [78]. Agüí et al, 2005, described a technique that coupled carbon-fibre microelectrodes with SWV to increase the surface area of the working electrode also provides fissures within its surface into which nitroaromatic compounds adsorb. Resulting detection limits obtained in phosphate buffer (PBS) were reported to be as low as $30 \mathrm{\mu g} \mathrm{L}^{-1}$ [79]. Cizek et al, 2010, reported a preliminary study into the integration of a preconcentration device to thermally desorb the TNT from the gaseous phase before electrochemical reduction with a screen-printed hydrogel-coated electrode using SWV. This preconcentration step allowed detection of TNT vapours from a solid sample upstream of the apparatus [80].

A technique involving a layer by layer assembly of alternate layers of mesoporous $\mathrm{SiO}_{2}$ (MSU) and polydiallyldimethylammonium chloride (PDDA) upon the surface of a glassy carbon electrode was found to increase pore volume, diameter and, therefore, surface area 
of the working electrode; this increased sensitivity to nitroaromatic compounds especially when at lower detection limits. This approach suffers, however, from an intrinsic issue with silica of poor conductivity which can have an effect on the performance of the sensor platform. The limit of detection for TNT was found to be $340 \mathrm{ng} \mathrm{L}^{-1}$ in aqueous solution [81]. Fu et al, 2010, reported the synthesis of $\mathrm{a} \mathrm{SiO}_{2}$ microsphere comprised of a mesoporous silica shell modified with 3-aminopropyltriethoxysilane (APTS) to attach amino functional groups. This system was applied to glassy carbon electrodes as a sensing layer for nitroaromatics, especially TNT. Using square wave voltammetry, a detection limit of $114 \mathrm{ng}$ $\mathrm{L}^{-1}$ in $0.5 \mathrm{~mol} \mathrm{~L}^{-1} \mathrm{NaCl}$ was achieved and $81 \%$ of original response was obtained after 30 days [82]. Ordered mesoporous carbon (OMC) has, more recently, been investigated to improve sensitivity towards nitro-explosives and the performance of the electrochemical sensor. The OMC provided a much improved surface area, as with the silica based system, and an enhanced conductivity which produced a sensor with lower limits of detection [83].

The detection of peroxide-based explosives has become increasingly important due to the ease at which some may be synthesised from commercially available substances and hence their link to terrorist activities. Lu et al, 2006, described a technique for rapidly monitoring liquid peroxide-based explosives using an electrode modified with Prussian-blue as an artificial peroxidase and amperometric detection of the resulting hydrogen peroxide generated [84]. Detection limits were reported as $7.4 \mathrm{\mu g} \mathrm{L}^{-1}$ for TATP in PBS after a $15 \mathrm{~s}$ irradiation time. Parajuli and Miao, 2009, reported an electrogenerated chemiluminescence (ECL) technique that was enhanced (by up to 20 times) by the inclusion of silver nitrate at the platinum electrode. This system involved the oxidation of HMTD by the electrogenerated species allowing a detection limit of $1 \mathrm{mg} \mathrm{L}^{-1}$ in acetonitrile to be achieved [85].

Wang and Pumera, 2006, produced a microchip flow-injection analysis for trace amounts of TNT. The authors described the need for 'lab-on-a-chip' technology to achieve a fast, simple and cheap alternative to laboratory-based techniques [86]. This approach used electro-osmotic flow to move samples through the microchip manifolds and measures response to TNT amperometrically. Amalgam mercury/gold disc electrodes were used due to their favourable signal-to-noise ratio and detection limits of $7 \mu \mathrm{g} \mathrm{L}^{-1}$ in sodium borate buffer were described, with the added advantages of a high-throughput system and minimal sample consumption.

A textile based electrochemical sensing system was described as a means to provide a wearable chemical sensor. Here, various textiles were analysed to assess performance as a screen-printed electrode with a breathable and waterproof fabric Gore-Tex (TM) being found to exhibit promising properties for use in this field. Properties such as, for example: 
hydrophobicity and printing quality on the fabric were found to afford the subsequent electrochemical activity of the sensors. Detection of nitroaromatic compounds was demonstrated and an initial assessment into the resilience of the fabric as a sensor platform was conducted successfully [87].

The development of single use processes to enable disposable electrochemical sensing has become more desirable to facilitate a portable explosive sensor. Chen et al, 2006, described the use of a Nafion (TM) coated, pre-anodised screen-printed carbon electrode that increased the sharpness of peaks and, therefore, the ease of identification of substituent groups upon the nitroaromatic compound. Recovery of TNT from spiked lake water was $95.7 \%$, with this complex matrix only affecting the sample slightly [88].

Bhalla et al, 2011, described a biosensor that detects picric acid effectively based on the inhibition of the Photosystem II (PSII) in the presence of explosives. Photosystem II is a protein complex involved in the electron chain reaction in photosynthesis. Gold screenprinted electrodes were functionalised with the PSII and the sensing system was based on the inhibition of the natural photosynthetic reaction by the presence of explosive compounds. Picric acid was found to compete with $Q_{B}$ plastoquinone for its binding site on the protein complex of PSII. This disrupts the electron transfer process and decreases the resulting photocurrent, which was observed through steady-state electrochemical interrogation. The detection limit in MES buffer for picric acid in this system was found to be $5.7 \mu \mathrm{g} \mathrm{L}^{-1}$ [89].

Yu et al, 2009, reported the combination of electrochemical and piezoelectric transduction mechanisms as a detection technique, using the ionic liquid $\mathrm{BMIBF}_{4}$ (1-methyl-3-butylimidazolium tetrafluoroborate) as both the electrolyte and the sorption solvent to enable this multi-faceted system. The accuracy of a system such as this was increased due to the validation that one system may have over the other [90].

\subsection{Immunochemical}

Immunochemical sensors exploit characteristics of the antibody-antigen reaction in such a manner that produces a device that can be highly specific to its target molecule. This feature and the fact that it is possible to produce antibodies for a specific purpose make this an expanding field of research into explosives detection.

A recent review by Smith et al, 2008, provides a more comprehensive report on not only immunochemical sensors, but also biosensors and biologically-inspired systems for explosive detection in general [91]. 
Anderson et al, 2006, reported a multiplexed immunoassay approach using a flow cytometer, the Luminex ${ }^{100}$, which contains 100 different sets of fluorescent latex microspheres, each of which is encoded by two fluorescent dyes. The ratio of the emission recorded at two different wavelengths enables identification of each set. The limit of detection for TNT in PBS was found to be $1.0 \mu \mathrm{g} \mathrm{L}^{-1}$ [92]. Detection of peroxide based explosives using immunoassays have been less reported. Anderson et al, 2010, described the comparison of two monoclonal and one polyclonal commercial antibodies as well as the development of llama polyclonal antibodies for use in the detection of PETN. As before, evaluation was performed with the Luminex ${ }^{100}$ flow cytometer. Binding was found to occur between bioconjugates of PETN and the antibodies but binding with the free PETN was limited [93]. This can often be the case when the target molecule is small and so further development within this area is necessary before detection of PETN in this manner becomes a possibility.

Surface Plasmon resonance (SPR) immunosensors act by detecting a change in the refractive index at the surface of the sensor due to an alteration in the binding of molecules immobilised on this surface. Where a large molecule binds with the immobilised antibody, a large signal is gained. Explosive molecules tend to only give rise to a small signal due to their relatively small size and this causes an issue with sensitivity, this is especially apparent in miniaturised systems. As such, amplification techniques have been investigated to improve detection of small analytes and competitive inhibition is often employed. Nagatomo et al, 2009, reported a novel oligo(ethylene glycol) (OEG)-based self-assembled monolayer upon a bare gold chip using an anti-DNT antibody for an indirect competitive binding effect. In the presence of DNT, there was an inhibition of surface binding, decreasing the SPR angle. This system exhibited high sensitivity for DNT, with a limit of detection of $20 \mathrm{ng} \mathrm{L}^{-1}$ in PBS [94]. A nano-scale biosensor chip surface modified with a polyamidoamine dendrimer was reported to enhance the antibody surface loading capacity while increasing the selectivity towards TNT molecules in a stable, easily regenerated system [95]. A schematic of these types of system is shown in figure 3 where an antigen of interest has been covalently immobilised on the SPR chip surface. If a solution of antibody mixed with a sample containing no antigen flows over the sensor surface, it binds to the immobilised antigen causing a large shift in resonance angle. However should the sample contain the antigen, there will be competition for the antibody between free and bound antigen, less antibody will therefore bind to the surface and a lower shift in resonance angle will be seen.

\subsection{Luminescence sensors}

\subsubsection{Principle}


Luminescence based sensors for detecting explosive compounds may be described as utilising either direct or indirect detection methods. Direct detection techniques utilises any fluorescence which the sample may emit itself or through inducement with a chemical reaction. Indirect detection involves the implication of explosives being present through their effect on a fluorescent material such as, for example, via quenching. While recent developments within this area are examined here, the reader is referred to a more comprehensive review of luminescence-based explosive detection methods [96].

\subsubsection{Recent advances}

Toal et al, 2006, reported a technique to visually detect the quenching of photoluminescence in the presence of nitroaromatic explosives using a metallole-containing polymer adsorbed on filter paper onto which a sample of the explosive compound was spray coated from acetone or fingerprinted from a solid sample. Under illumination with UV light, quenching was observed and detection limits were as low as $5 \mathrm{ng}$ for TNT. One issue with a technique such as this is that observation of a colour change can be a subjective activity and so combining this with another, more qualitative system or an automated approach may be necessary [97]. This group's work was continued to make the sensor more selective by incorporating a tandem process that first quenches the metallole in the presence of nitroaromatics as described above. A thin film of 2,3-diaminonaphthalene (DAN) is then applied which cancels the polymetallole luminescence and, in the presence of nitroamine and/or nitrate-ester explosives, a reaction with the DAN forms a blue luminescent complex [98]. An investigation into synthesising polymers and copolymers and their relevance to explosive detection was also undertaken by this group which reported some polymers were able to detect nitroaromatic, nitro-amine and nitro-ester explosive compounds [99]. Further work was reported that coupled the tandem process mentioned previously with an efficient blue-emitting silafluorene-fluorene copolymer system that was able to detect trace particulates of samples of all of the nitro-based explosives, allowing detection limits as low as $1 \mathrm{pg} \mathrm{cm}^{-1}$ [100].

A fluorescent film produced as a self-assembled monolayer has been described by Du et al, 2010. This group introduced a benzene ring as the spacer component to ensure favourable packing of the pyrene moieties as they self assembled. The effect of the addition of the aromatic structure was an increased quenching of the fluorescence emitted when in the presence of nitroaromatic compounds, most especially with picric acid where the detection limit was established at $2.3 \mathrm{\mu g} \mathrm{L}^{-1}$ in water. This is believed to be due to the extension outside the film of the pyrene moieties and the restriction of motion caused by the inclusion of benzene [101]. 
Shi et al, 2008, described the quenching effect that nitroaromatic compounds have on oleic acid covered CdSe quantum dots. This work reported detection limits around $10^{-6}$ to $10^{-7} \mathrm{~mol}$ $\mathrm{L}^{-1}$ for a range of compounds, for example $340 \mu \mathrm{g} \mathrm{L}^{-1}$ for TNT in chloroform, making this a viable screening technique. Further technique optimisation is necessary before it may be seen as a workable alternative to fluorescent polymers [102]. The combination of quantum dots with a dendrimer, such as PAMAM (poly(amido amine)) generation 4 [103], has been reported to increase biocompatibility and biostability as well as increasing reactivity. Such improvements increased water solubility and as a consequence signal output.

Photo-fragmentation of nitro-based explosives at $193 \mathrm{~nm}$ has been demonstrated by Monterola et al, 2008. At this wavelength the $\mathrm{NO}_{2}$ moieties are released from the compound and may be detected through their chemiluminescent interaction with a solution of luminol. Trace amounts of PETN vapour were detected at $3 \mathrm{ppb}\left(40 \mathrm{ng} \mathrm{L}^{-1}\right)$ and analysis of PETN in a soil matrix yielded a LOD range of $0.5-4.3 \mu \mathrm{g} \mathrm{g}^{-1}$. This technique is fast and simple but does not identify the specific molecule, giving only a general identification of a nitro-based sample being present [104].

Ponnu and Anslyn, 2010, produced a cyclodextrin (CD) sensor by combining the CD with a fluorophore, bis(phenylethynyl)anthracene (BPEA), to produce a cyclodextrin inclusion complex. The cavities of this complex are less polar than water and so are able to extract hydrophobic molecules from aqueous environments. When applied to aqueous solutions containing explosives, quenching occurred in the presence of nitroaromatic compounds but not other nitro-based explosives. Quenching effects were found to be greater with the complex as opposed to the fluorophore alone [105].

Caron et al, 2010, reported a portable fluorescent detector capable of ultra-trace detection of the nitroaromatic compounds TNT and DNT, which was unaffected by environmental humidity or interfering substances [106, 107]. This detector utilised a specific fluorescent conjugated polymer which adsorbed nitroaromatic vapours present in airborne samples with a concurrent decrease in fluorescence. Although at present this device only detects nitroaromatics, a multi-faceted design may be possible using several fluorescent material platforms. A sensor array of commercially available fluorescent polymers was evaluated by Woodka et al, 2010, to attempt to limit the possibility of false positives due to a high concentration of non-explosive electron withdrawing compounds (EWC). The responses gained from a variety of explosives, explosive related compounds and non-explosive EWCs in water were analysed using principal component and linear discriminant analyses. The array was found to discriminate between the explosive, non-explosive and explosive related 
electron withdrawing compounds and in this way was demonstrated as a platform approach for minimising the likelihood of false positives [108].

\section{Nanotechnology}

Nanotechnology has become a rapidly expanding area of research over recent years as techniques and knowledge have developed. Materials often possess unique characteristics when in a nanoscale form as compared to bulk materials and as such, the incorporation into existing techniques is an active area of research to enhance sensitivity and selectivity. For example, the benefits of using such materials as carbon nanotubes are that they display enhanced detection sensitivity compared to sensors incorporating other carbon platforms (possibly due to increased surface area,) they have electrocatalytic effects, are mechanically strong and flexible and have excellent electrical and thermal conductivity. Nanoparticle systems have also been used such as metal nanoparticles, again they can lead to enhanced sensitivities especially in electrochemical systems due to increased surface areas, catalytic effects and improving electrical conductivity. Metal nanoparticles can also have beneficial effects in optical sensors due to increased surface areas and a number of optical effects such as surface enhanced Raman spectroscopy, described later in this section.

\subsection{Molecularly imprinted polymers}

\subsubsection{Principle}

Molecularly imprinted polymers (MIPs) are generated through both covalent and non-covalent interactions of functional monomers with the molecule of interest or its analogues, acting as a template. Figure 4 shows schematically the formation of a MIP by crosslinking around a template. MIPs allow the formation of molecules with recognition sites specific for a target analyte producing a substance specific coating which may then be incorporated onto a sensing platform. MIPs are stable and robust which accounts for the interest in researching possible uses for them as sensing materials. A more extensive review into the use and synthesis of these polymers can be found in the literature [109].

The proposal of MIPs for the detection of explosive compounds was first described by Chianella et al, 2004 [110], where MIPs were designed for PETN, RDX, Tetryl and TNT. A patent filed by Schwartz et al, 2005, described an array of MIP coated fibre-optic cables which, when coupled to a suitable algorithm program, is capable of identifying either single or multiple explosive target molecules [111].

\subsubsection{Recent advances}


More recently, research has been undertaken into the optimisation of polymerisation techniques and assessing the merit of various monomers for the synthesis and subsequent specificity towards explosives compounds. Bunte et al, 2007, described the comparison of various monomer/solvent complexes and the use of a spray gun, alongside conventional techniques, to apply the thin film to a quartz crystal microbalance (QCM). Response times for TNT vapour were found to be in the pg per $\mu \mathrm{g}$ MIP per minute range [112]. The same group, based at the Fraunhofer Institute for Chemical Technology, described further work into MIP application using both a nanoplotter and a spin coating device to assess the resulting quality of the layers [113] as well as the use of a continuous segmented flow microreaction process to allow uniform sized pre-polymer droplets to be generated. This enabled the size required to be defined, so minimising the need to sieve before use in columns [114].

Stringer et al, 2010, described the use of quantum dots as the fluorescent species in a fluorescent-labelled MIP system. The quantum dots, rather than being incorporated into the polymer matrix, were inserted post-processing to extend the shelf-life of the system. Lower limits of detection were found to be 30.1 and $40.7 \mu \mathrm{mol} \mathrm{L}^{-1}$ for aqueous DNT and TNT, respectively [115]. Whilst this system was unable to match detection limits of other MIP based detection techniques [116], response times were found to be as low as 1 minute.

Nie et al, 2011, described a two dimensional approach to molecular imprinting for the detection of TNT. This two-dimensional approach was expected to improve limitations such as incomplete template removal and slow mass transfer associated with traditional MIP. The molecularly imprinted monolayer, MIM, was prepared upon a Au nanoparticle modified glassy carbon electrode (AuNP-GCE) to enable electrochemical detection of TNT. TNT templates were preadsorbed on the surface of the AuNP-GCE the alkanethiols then self-assemble before removal of templates. These MIMs were found to have good selectivity towards TNT above other nitroaromatic compounds with a detection limit of $3 \mu \mathrm{g} \mathrm{L}^{-1}$ and this enabled the system to be successfully applied to environmental water samples [117].

\subsection{Nanotubes}

The unique properties of nanotubes have generated great interest towards the study and development of this field of research. These include, for example, their electrical properties as either conductors, insulators or semiconductors, depending on the structure and their high thermal conductivity in the axial direction while their thermal conductivity is low in the lateral direction. There are many more examples of their unique kinetic, optical and mechanical properties that ensure this area of study is continually expanding [118]. 
Wang et al, 2004, reported the surface modification of glassy carbon electrodes with multi-walled carbon nanotubes (MWCNT) for the detection of TNT with adsorptive stripping voltammetry (ASV). Modification of the electrode in this manner aided the accumulation of TNT at the electrode surface due to the increased surface area. This resulted in quantification of TNT down to the sub- $\mu \mathrm{g} \mathrm{L}^{-1}$ level and a LOD of $0.6 \mu \mathrm{g} \mathrm{L}^{-1}$ [119]. It was also discovered that this system performed better in a seawater matrix, with increased sensitivity when compared to a synthetic $\mathrm{NaCl}$ solution. A number of issues with selectivity were reported, however, since other nitroaromatic compounds were found capable of interference.

Chen et al, 2010, reported the use of semiconducting single walled carbon nanotubes (SWCNT) as wearable chemical sensors, firstly positioning the SWCNT in an aligned array on quartz using chemical vapour deposition and then transferring the array onto textile. This coated textile section was then incorporated onto a chip carrier with an electrical and gas feed, essentially becoming a wearable transistor. In air, the LOD for TNT was found to be 8 $\mathrm{ppb}\left(80 \mathrm{ng} \mathrm{L}^{-1}\right)$. The same group also reported the production of metal oxide nanowires with a LOD for TNT vapour of $600 \mathrm{ng} \mathrm{L}^{-1}[120]$.

A SWCNT based chemiresistive immunosensor was described by Park et al, 2010, which provided a label-free, sensitive and selective technique for detection of nitroaromatic explosives. The SWCNT was first modified with trinitrophenyl (TNP), an analogue of TNT, which was then functionalised with an anti-TNP single chain antibody. This antibody has a greater affinity for TNT and thus the introduction of TNT caused a large change in the resistance of the system with the detection range of $5 \mathrm{ng} \mathrm{L}^{-1}$ to $50 \mathrm{\mu g} \mathrm{L}^{-1}$ TNT in PBS and environmental water samples being reported [121].

As previously mentioned, detection of peroxide based explosives can be complex due to these compounds containing neither the nitro groups nor aromatic behaviours traditionally used for analysis [122]. Banerjee et al, 2009, suggested the use of a one-dimensional titania $\left(\mathrm{TiO}_{2}\right)$ nanotube array where metal ions, in this case zinc $\left(\mathrm{Zn}^{2+}\right)$, are coated upon the surface. When present in argon the TATP vapour bonded to the metal ions and the signal current output, as detected by a potentiostat, increased by between 3 to 5 orders of magnitude although this was found to be prone to saturation for TATP in air under ambient conditions [123].

The use of both carbon nanotubes and metallic nanoparticles were described by Hrapovic et al, 2006, for the electrochemical detection of nitroaromatic compounds. The nanocomposite was composed of a SWCNT with copper nanoparticles within a Nafion matrix, selected for their stability, reproducibility, low background current and prominent peak display with cyclic 
voltammetry and anodic stripping voltammetry, ASV. A detection limit of $1 \mu \mathrm{g} \mathrm{L}^{-1}$ was reported in tap water, river water and washed contaminated soil samples [124].

Guo et al, 2011, reported the development of an ionic liquid graphene nanosheet used with a glassy carbon electrode for the detection of TNT. The nanosheets were synthesised as described by [125] and used to detect the presence of TNT as it was electrochemically reduced. Comparison data illustrated a distinct improvement in signal when compared to plain glassy carbon electrodes or those functionalised with ionic liquid carbon nanotubes; and a detection limit of $4 \mu \mathrm{g} \mathrm{L}^{-1}$ in PBS was reported [126].

\subsection{Nanoparticles}

Jiang et al, 2008, described a simple colorimetric visualisation of TNT at picomolar levels based on the donar-acceptor (D-A) interaction between TNT and primary amines - in this case cysteamine. The cysteamine acts as both primary amine and stabilizer to the gold nanoparticles (Au NP); introduction of TNT into the aqueous solution caused aggregation of these amine covered Au NPs which resulted in a colour change from red to violet which can be observed without further analysis. An addition of $114 \mathrm{pg} \mathrm{L}^{-1}$ of TNT changed the solution colour such that it could be visualised by the naked eye [127].

Surface-enhanced Raman scattering (SERS) is a technique that enhances the intensity of Raman scattering spectra through the proximity of a molecule to a roughened metal surface or, in the case of nanomolecules, between gaps in nanostructures. Dasary et al, 2009, described a SERS probe coated with gold nanoparticle-cysteine conjugates; this system was able to form aggregating Meisenheimer complexes in water in the presence of TNT. A result of this was hot spot formation and an enhancement of the Raman signal intensity, allowing TNT to be detected at a concentration of $0.45 \mathrm{ng} \mathrm{L}^{-1}[128]$...A similar technique was described by Yang et al, 2010, using functionalised silver nanoparticles coated on silver molybdate nanowires with crosslinking provided by p,p'-dimercaptoazobenzene (DMAB). TNT was detected in this case at concentrations of $0.23 \mathrm{ng} \mathrm{L}^{-1}$ [129]. The detection of peroxide based explosives has also been described using a similar approach. Chang et al, 2009, reported a SERS-active nanoporous substrate based on porous alumina membranes combined with mixed nanoclusters comprising gold nanorods and gold nanoparticles. The plasmon resonance from hot spots produced by the above system photo-decompose molecules of HMTD enabling analysis of the fragments. The LOD has been interpolated as 2 pg HMTD in $10 \mu \mathrm{L}$ of acetonitrile [130]. A self-assembled gold octahedral array has been described that used a droplet evaporation process. This process produced a nanoparticle array with nanoscale interparticle gaps which provide an enhancement to the SERS detection of TNT deposited from ethanol solution through improved sensitivity and 
reproducibility [131]. There has been significant work within this area to establish optimal working conditions of the system including, for example, the effect of exposure time and temperature on the resulting signal $[132,133]$ as well as addressing false positives due to musk based perfumes of similar structure to TNT [134], in this case it was found that the compounds musk ketone and musk xylene can be distinguished from TNT using the SERS technique.

An imprinted composite coating of bisaniline-gold nanoparticles was developed using Kemp's acid as an imprinting molecule upon a gold surface for the detection of RDX. This technique used surface plasmon resonance (SPR) which reveals changes in the refractive index occurring due to adsorption or desorption at the surface. Detection of RDX was possible at $2.6 \mathrm{pg} \mathrm{L}^{-1}$ in HEPES buffer due to the formation of $\pi$-donor-acceptor complexes between RDX and the bisaniline bridging units [135]. Kawaguchi et al, 2008, describe the use of gold nanoparticles on the immunosurface within a miniaturised SPR system that amplified the signal for TNT by four times that which is seen when the gold nanoparticle was absent [136].

Wang et al, 2008, reported electrochemical competitive displacement immunoassays for the detection of TNT. Poly(guanine)-functionalised silica nanoparticles were complexed with anti-TNT coated magnetic beads using an analogue of TNT, trinitrobenzene. When exposed to TNT the analogue was displaced and there was an increase of guanine in the solution. The magnetic beads were removed and the solution electrochemically interrogated upon a screen printed electrode in a solution of PBS with mediator. The limit of detection for this system was found to be $\sim 100 \mathrm{ng} \mathrm{L}^{-1}[137]$.

Chen et al, 2010, described a chemosensor based on pyrene-functionalised Ru (ruthenium) nanoparticles, using 1-vinylpyrene $(R u=V P y)$ and 1-allylpyrene $(R u=A P y)$. Both of these particles exhibited enhanced detection of nitroaromatic compounds in dimethylformamide as compared to monomeric pyrene; and of the two particles under examination $\mathrm{Ru}=\mathrm{VPy}$ nanoparticles displayed higher sensitivity. Increased nitration on the aromatic ring increased the response, and for this reason TNT exhibited the greatest fluorescence quenching of the nitroaromatics under consideration [138].

\section{Quartz crystal Microbalance}

\subsubsection{Principle}

The quartz crystal microbalance utilises the resonance frequency change due to changes in mass upon the crystal surface as a means to detect the presence of a substance of interest. This technique is further enhanced through coating the surface with various compounds 
which help provide specificity to this system. Although this paper will relate the use of a QCM in relation to the field of nanotechnology, the reader is referred to a comprehensive review of the many uses of QCM [139].

\subsubsection{Recent advances}

Larsson et al, 2006, reported a potential selective detector chip for TNT using thiol self-assembly with a TNT analogue upon a gold biochip and a subsequent competitive labelfree immunoassay. Several combinations of TNT analogue/organosulphur compounds were evaluated as a possible self-assembled monolayer (SAM) for this system and the analogue dissociation was monitored with both a QCM and via surface plasmon resonance (SPR). The detection limit for TNT was within the 1-10 $\mathrm{g} \mathrm{L} \mathrm{L}^{-1}$ range in PBS depending on the TNT-analogue used [140], with one analogue, ANA1, presenting shorter recovery times after exposure and a higher relative response to TNT.

Cerruti et al, 2009, further investigated the selective detection of TNT and DNT using QCM with a polymer-oligopeptide coating upon a gold chip capable of providing a stable and high density set of receptors with selective binding capabilities. This system was capable of providing real-time detection, in water, of TNT whilst the presence of DNT exhibited no resonance frequency change [141]. A different approach by Lubczyk et al, 2010, was to combine several differently coated microbalances in an array to distinguish the peroxide based explosive TATP from chemically related compounds. Analytical detection methods for TATP often rely on the detection of hydrogen peroxide $\left(\mathrm{H}_{2} \mathrm{O}_{2}\right)$ as an indicator of its presence; however, as $\mathrm{H}_{2} \mathrm{O}_{2}$ can be found in other substances there is a risk of false positives from merely detecting this substance. This work attempted to address this issue using a combination of a modified phenylene dendrimer, a cyclodextrin and a cholic acid derivative as the separate coatings on an array of QCMs. Response times were found to be in the range of a few seconds and rapid system recovery was also possible. Combining this approach with high frequency QCM a lower limit of detection for TATP vapour in nitrogen was reported at $1 \mathrm{ppm}\left(6.6 \mu \mathrm{g} \mathrm{L}^{-1}\right)$ [142].

Yu et al, 2009, described a combination of electrochemical and piezoelectrical transduction techniques for the sensitive and selective detection of nitroaromatic compounds. This system used an ionic liquid, $\mathrm{BMIBF}_{4}$, as both the electrolyte for the amperometric sensing and the sorption solvent to coat the QCM. The amperometric and QCM sensing systems were integrated onto a single quartz chip permitting miniaturisation. Sensing was performed in the $0-70 \mu \mathrm{g} \mathrm{L}^{-1}$ region for ethylnitrobenzene, validating the combination of these two systems and the use of ionic liquids as both solvent and electrolyte in a miniaturised system such as this [90]. 


\section{Thin Films Sensors}

The design of selective polymers for the detection of explosive compounds has been described earlier. Tenhaeff et al, 2010, employed initiated chemical vapour deposition (iCVD) to deposit a nitro-aromatic selective polymer, poly(4-vinylpyridine), inside microfabricated trenches. This coating was subsequently coated with a gold/palladium electrically conductive layer. When the polymer coating absorbed the analyte vapour of interest it swelled producing an interaction between the conductive layers on either side of the trough and this contact can subsequently be measured electrically. Although this system demonstrated the transduction of a chemical interaction into an observable measurement, there were several issues that would need to be addressed before translation into a viable detection device, such as the switch presently being irreversible and the length of response times - the shortest for nitrobenzene being 10.2 minutes. The authors do, however, claim concentration and mass limits of detection for TNT as low as $9.5 \mathrm{ng} \mathrm{L}^{-1}$ and $3 \mathrm{fg}$ respectively through modelling based on optimal conditions [143].

Long et al, 2009, reported an electrospun nanofibrous film doped with a fluorescent conjugated polymer (CP) for the detection of DNT in chloroform. CPs have greater fluorescent quantum yields and amplified sensory responses as compared to small fluorescent molecules, although they experience self-aggregation and thus self fluorescent quenching. The authors employed electrospinning to construct a nanofibrous film that decreased opportunities for self-aggregation. The polymer was further doped with a supporting matrix and a porogen to increase the surface area and porosity of the surface; this enabled target analytes to diffuse close to the sensing elements so increasing the quenching capabilities [144].

Lock et al, 2009, described the use of a self-assembled monolayer upon the surface of a microcantilever, which undergoes chain polymerisation in the presence of peroxide radicals which are produced when the sample vapours are passed through a heating filament. This sensor was capable of detecting hydrogen peroxide and tertbutyl peroxide, leading to the hope that it may be suitable for use within a peroxide explosive sensor. This system also displayed reversibility, returning to baseline without need for thermal regeneration [145] and was reported as being selective to peroxide vapours, although this may not be sufficiently discriminating to prevent some false positives. 


\section{Conclusions and future outlook}

It can be observed that almost all analytical techniques addressed in this review have undergone significant changes to improve one or more aspects of their working practises over the last five years; including, for example: sensitivity, specificity, cost, ease of use and miniaturisation. Further advancement will be necessary to provide a system that incorporates all aspects of an ideal explosive identification technique due to the inherent issues that are associated with this - low volatility of explosive vapours, concealment, interferences and the actual damage caused by a false response. Significant improvements have been made in the portability of apparatus; spectroscopic techniques, such as IMS and mass spectrometry, which were largely stationary are now become field deployable. Terahertz spectroscopy, once beleaguered with issues, has been realised as a technique that can identify explosives and other concealed objects beneath clothing and within luggage. Nanotechnology over the last decade has become increasingly important, with research to incorporate new nano-based aspects into existing technologies to improve sensitivity, selectivity and portability.

We have within this review discussed many of the applications that require explosive detection and the capabilities of some of the current commercial systems are shown in table 1. There appear to be many promising methods that are being developed as alternatives to these systems and the utilisation of these various technologies will depend on the particular application. For applications that require not only high sensitivity but also an immediate response, such as airport security, the most promising systems appear to those based on either mass spectroscopy which is the basis of many of the detection systems currently in use. These offer a rapid response and can detect low levels of most explosive materials, as well as many other hazardous chemicals. Other technologies that could compete with these are optical systems, such as those using conjugated fluorescent polymers which could match the sensitivity and speed of response, although it is unlikely that they would be able to detect as wide a range of analytes. Some of the nanotechnology based methods, utilising for example carbon nanotubes which may display rapid changes in conductivity on adsorption of vapours of interest may also be suitable, although one challenge is the selectivity of such systems.

For detection of explosive devices in other environments (landmines, roadside bombs etc) the most important factor is probably the ability to detect at a safe distance, rather than having to approach the device. Of great interest therefore are optical laser-based techniques such as the Raman systems described earlier which allow detection of explosives at stand- 
off distances as high as 180 metres. They are also of interest because of their ability to detect explosives in sealed containers such as glass or plastic bottles.

For forensic investigations and environmental monitoring, rapid detection is usually not a matter of such urgency so other techniques can compete. In the case of forensic examination, most of this is still lab based but the techniques used such as mass spectrometry are becoming much smaller and in some cases are portable. One challenge for environmental monitoring is that usually large areas can be involved, such as river basins and this means a large number of samples may be required. Laboratory based techniques are often expensive and require trained personnel, leading to cost and time issues. It is in this context that the use of such methods as biosensors or molecular imprinted polymers become suitable. They display high selectivity and specificity and can often be made cheaply, for example the use of cheap screen-printed electrodes has allowed the construction of disposable one-shot biosensors, as typified by commercial home glucose sensors. Utilisation of this technology will allow the measurement of large number of samples at a much reduced cost, with the possibility that they could be used as a screening process. Large areas could be investigated to determine location of areas of high contamination which can then be sampled for in depth off-site analysis.

The field of explosives detection is certain to remain and active and wide-ranging area of research due to increased demand for homeland security in the face of perceived terrorist threats as well the remediation of environments that already pose a high risk - such as clearing of minefields. One of the most important aspects of these technologies is that of portability and much research is being undertaken into the miniaturisation of existing technologies. Nanotechnology has an important role to play in this as well as also enabling the development of new technologies. Improving the sensitivity and specificity of explosive detection technology are principles that continue to be important; lower detection limits for many materials have improved considerably and work in this area remains a competitive field of research.

\section{Acknowledgements}

The authors would like to acknowledge the Engineering and Physical Sciences Research Council (EPSRC) for the funding and sponsorship of an EngD studentship for J.S.C. 
Figure Legends

Figure 1 - A schematic of a simplified ion mobility spectrometer

Figure 2 - A schematic of the Cavity Ringdown arrangement as described by Snels et al, 2010 [65]. Reprinted from Chem. Phys. Lett (2010), with permission from Elsevier.

Figure 3 - A schematic of the principle of competitive inhibition assay on a surface plasmon resonance immunosensor (a) represents the decrease in resonance shift angle upon binding of pure antibody to the immobilised analyte (b) competitive reaction between immobilised and free antigen for the antibody resulting in lower frequency shift.

Figure 4 - Schematic of the development of a molecularly imprinted polymer 
Table 1. Comparison of commercial explosive detection devices.

\begin{tabular}{|c|c|c|c|c|}
\hline Company & $\begin{array}{l}\text { Cost } \\
(\$ K)\end{array}$ & $\begin{array}{l}\text { Detection } \\
\text { method }\end{array}$ & $\begin{array}{l}\text { Advertised } \\
\text { Sensitivity }\end{array}$ & Weight \\
\hline $\begin{array}{c}\text { Barringer Instruments, Inc. } \\
\text { IONSCAN } 350\end{array}$ & 0.25 & IMS & $50 \mathrm{pg}$ to $200 \mathrm{pg}$ & $105 \mathrm{lb}$. \\
\hline $\begin{array}{c}\text { Barringer Instruments, Inc. } \\
\text { IONSCAN } 400\end{array}$ & 50 & IMS & $50-200 \mathrm{pg}$ & $60 \mathrm{lb}$. \\
\hline $\begin{array}{c}\text { Electronic Sensor Tech., Inc. } \\
\text { EST Model } 4100\end{array}$ & 60 & GC/SAW & 100 ppb & $35 \mathrm{lb}$. \\
\hline $\begin{array}{l}\text { EXPRAY Field Test Kit Model } \\
\text { M1553 }\end{array}$ & 25 & Colormetry & $\begin{array}{l}20 \text { ng of most } \\
\text { nitrated high } \\
\text { explosives }\end{array}$ & $\begin{array}{c}3 \\
\text { aerosols, } \\
1 \mathrm{lb}\end{array}$ \\
\hline GE EntryScan3 “Puffer” & 160 & IMS & $\begin{array}{l}16 \text { common } \\
\text { explosives }\end{array}$ & Custom \\
\hline $\begin{array}{l}\text { Intelligent Detection Systems } \\
\text { ORION }\end{array}$ & 70 & GC/IMS & $\mathrm{pg}$ to $\mathrm{ng}$ & $240 \mathrm{lb}$. \\
\hline $\begin{array}{l}\text { Intelligent Detection Systems } \\
\text { ORION Mail Scanner }\end{array}$ & 75 & GC/IMS & pg to $n g$ & $240 \mathrm{lb}$. \\
\hline $\begin{array}{l}\text { Intelligent Detection Systems } \\
\text { ORION Plus }\end{array}$ & 155 & GC/IMS & $\mathrm{pg}$ to $\mathrm{ng}$ & $240 \mathrm{lb}$. \\
\hline $\begin{array}{l}\text { Intelligent Detection Systems } \\
\text { ORION Walk-Through }\end{array}$ & 300 & GC/IMS & $\mathrm{pg}$ to $\mathrm{ng}$ & Custom \\
\hline $\begin{array}{l}\text { Intelligent Detection Systems } \\
\text { SIRIUS }\end{array}$ & 75 & GC/IMS & $\mathrm{pg}$ to $\mathrm{ng}$ & $240 \mathrm{lb}$. \\
\hline $\begin{array}{c}\text { Intelligent Detection Systems V- } \\
\text { bEDS }\end{array}$ & custom & GC/IMS & $\mathrm{pg}$ to $\mathrm{ng}$ & Custom \\
\hline $\begin{array}{c}\text { Ion Track Instruments Exfinder } \\
152\end{array}$ & 5 & GC/ECD & $\begin{array}{c}20 \mathrm{ng} \text { of most } \\
\text { nitrated high } \\
\text { explosives }\end{array}$ & $1.5 \mathrm{lb}$. \\
\hline Ion Track Instruments ITEMISER & 44 & IMS & $100 \mathrm{pg}$ to $300 \mathrm{pg}$ & $43 \mathrm{lb}$. \\
\hline $\begin{array}{c}\text { Ion Track Instruments ITMS } \\
\text { Vapor Tracer }\end{array}$ & 38 & IMS & $100 \mathrm{pg}$ to $300 \mathrm{pg}$ & $7 \mathrm{lb}$. \\
\hline $\begin{array}{c}\text { Ion Track Instruments Model } 85 \\
\text { Dual scan }\end{array}$ & 52 & GC/ECD & $\begin{array}{l}1 \text { part EGDN vapor } \\
\text { in } 10^{11} \text { parts air }\end{array}$ & $600 \mathrm{lb}$. \\
\hline $\begin{array}{l}\text { Ion Track Instruments Model } 85 \\
\text { Entry Scan }\end{array}$ & 52 & GC/ECD & $\begin{array}{l}1 \text { part EGDN vapor } \\
\text { in } 10^{11} \text { parts air }\end{array}$ & $600 \mathrm{lb}$. \\
\hline Ion Track Instruments Model 97 & 20 & GC/ECD & $\begin{array}{l}\text { most nitrated high } \\
\text { explosives }\end{array}$ & $40 \mathrm{lb}$ \\
\hline $\begin{array}{c}\text { JGW International, Ltd. Graseby } \\
\text { GVD4 }\end{array}$ & 5 & GC/ECD & $\begin{array}{l}\text { explosive vapor } \\
\text { exceeding } 1 \text { in } 10^{9}\end{array}$ & $1.6 \mathrm{lb}$ \\
\hline $\begin{array}{c}\text { JGW International, Ltd. Graseby } \\
\text { GVD6 }\end{array}$ & 16 & IMS & $\begin{array}{l}\text { explosive vapor } \\
\text { exceeding } 1 \text { in } 10^{9}\end{array}$ & $21 \mathrm{lb}$. \\
\hline $\begin{array}{c}\text { JGW International, Ltd. Graseby } \\
\text { PLASTEC }\end{array}$ & 35 & IMS & $\begin{array}{l}1 \text { nanogram of TNT, } \\
\text { NG, RDX, PETN }\end{array}$ & $38 \mathrm{lb}$. \\
\hline MSA Instrument Division FIS & 29 & FIS & 10 to $1000 \mathrm{ppt}$ & $20 \mathrm{lb}$. \\
\hline Scintrex/IDS EVD-3000 & 23 & TR & $\begin{array}{l}<1 \text { ppb or }<100 \mathrm{ng} \\
\text { for particulate }\end{array}$ & $7 \mathrm{lb}$. \\
\hline Scintrex/IDS EVD-8000 & 43 & GC/ECD & $\begin{array}{c}<50 \text { ppt or }<5 \text { ng for } \\
\text { particulate }\end{array}$ & $48 \mathrm{lb}$ \\
\hline Smiths, IONSCAN 500DT & 49 & IMS & $>40$ substances & $43 \mathrm{lb}$ \\
\hline $\begin{array}{l}\text { Thermedics Detection, Inc. EGIS } \\
\text { Model } 3000\end{array}$ & 150 & GC/CL & $\begin{array}{l}\text { all nitrogen based } \\
\text { explosives }\end{array}$ & $400 \mathrm{lb}$ \\
\hline Thermedics Detection, Inc. & 300 & $\mathrm{GC} / \mathrm{CL}$ & all nitrogen based & Custom \\
\hline
\end{tabular}




\begin{tabular}{|c|c|c|c|c|}
\hline SecurScan Portal & & & explosives & \\
\hline VIKING Instruments Spectra Trak & 70 & GC/MS & low ppb by volume & $150 \mathrm{lb}$. \\
\hline XID Corporation, XID Model T-54 & 13 & GC/ECD & $0.01 \mathrm{ppb}$ & $18 \mathrm{lb}$. \\
\hline
\end{tabular}

From: "Guide for the Selection of Commercial Explosives Detection Systems for Law

Enforcement Applications", NIJ Guide 100-99. C. L. Rhykerd, D. W. Hannum, D. W. Murray, J. E. Parmeter, National Institute of Justice.

$\mathrm{CL}=$ chemiluminescence, $\mathrm{ECD}=$ electron capture detector, $\mathrm{SAW}=$ surface acoustic wave, $\mathrm{TR}=$ thermal redox . 
[1] R.G. Ewing, D.A. Atkinson, G.A. Eiceman, G.J. Ewing, A critical review of ion mobility spectrometry for the detection of explosives and explosive related compounds, Talanta. 54 (2001) 515-529.

[2] R.G. Ewing, M.J. Waltman, Mechanisms for negative reactant ion formation in an atmospheric pressure corona discharge, Int. J. Ion Mobil. Spectrom. 12 (2009) 65-72.

[3] T. Khayamian, M. Tabrizchi, M.T. Jafari, Analysis of 2,4,6-trinitrotoluene, pentaerythritol tetranitrate and cyclo-1,3,5-trimethylene-2,4,6-trinitramine using negative corona discharge ion mobility spectrometry, Talanta. 59 (2003) 327-333.

[4] M.J. Waltman, P. Dwivedi, H.H. Hill Jr., W.C. Blanchard, R.G. Ewing, Characterization of a distributed plasma ionization source (DPIS) for ion mobility spectrometry and mass spectrometry, Talanta. 77 (2008) 249-255.

[5] M. Tabrizchi, V. ILbeigi, Detection of explosives by positive corona discharge ion mobility spectrometry, J. Hazard. Mater. 176 (2010) 692-696.

[6] J.S. Babis, R.P. Sperline, A.K. Knight, D.A. Jones, C.A. Gresham, M.B. Denton, Performance evaluation of a miniature ion mobility spectrometer drift cell for application in hand-held explosives detection ion mobility spectrometers, Anal. Bioanal. Chem. 395 (2009) 411-419.

[7] S. Zimmermann, N. Abel, W. Baether, S. Barth, An ion-focusing aspiration condenser as an ion mobility spectrometer, Sens Actuators, B Chem. 125 (2007) 428-434.

[8] M. Martin, M. Crain, K. Walsh, R.A. McGill, E. Houser, J. Stepnowski, S. Stepnowski, H.-. Wu, S. Ross, Microfabricated vapor preconcentrator for portable ion mobility spectroscopy, Sens Actuators, B Chem. 126 (2007) 447-454.

[9] A.B. Kanu, C. Wu, H.H. Hill Jr., Rapid preseparation of interferences for ion mobility spectrometry, Anal. Chim. Acta. 610 (2008) 125-134.

[10] J. Yinon (Ed.), Counterterrorist Detection Techniques of Explosives, 1 ed., Elsevier, Oxford, UK, 2007.

[11] Y. Song, R.G. Cooks, Atmospheric pressure ion/molecule reactions for the selective detection of nitroaromatic explosives using acetonitrile and air as reagents, Rapid Commun. Mass Spectrom. 20 (2006) 3130-3138.

[12] Y. Takada, H. Nagano, M. Suga, Y. Hashimoto, M. Yamada, M. Sakairi, K. Kusumoto, T. Ota, J. Nakamura, Detection of military explosives by atmospheric pressure chemical ionization mass spectrometry with counter-flow introduction, Propellants Explos Pyrotech. 27 (2002) 224-228.

[13] C. Mullen, A. Irwin, B.V. Pond, D.L. Huestis, M.J. Coggiola, H. Oser, Detection of explosives and explosives-related compounds by single photon laser ionization time-of-flight mass spectrometry, Anal. Chem. 78 (2006) 3807-3814.

[14] R.G. Cooks, Z. Ouyang, Z. Takats, J.M. Wiseman, Ambient mass spectrometry, Science. 311 (2006) 1566-1570. 
[15] D.R. Justes, N. Talaty, I. Cotte-Rodriguez, R.G. Cooks, Detection of explosives on skin using ambient ionization mass spectrometry., Chem. Commun. (Camb. ) (2007) 2142-2144.

[16] I. Cotte-Rodríguez, H. Hernández-Soto, H. Chen, R.G. Cooks, In situ trace detection of peroxide explosives by desorption electrospray ionization and desorption atmospheric pressure chemical ionization, Anal. Chem. 80 (2008) 1512-1519.

[17] Z. Takáts, J.M. Wiseman, B. Gologan, R.G. Cooks, Mass spectrometry sampling under ambient conditions with desorption electrospray ionization, Science. 306 (2004) 471-473.

[18] R.B. Cody, J.A. Laramée, H.D. Durst, Versatile new ion source for the analysis of materials in open air under ambient conditions, Anal. Chem. 77 (2005) 2297-2302.

[19] J.M. Nilles, T.R. Connell, S.T. Stokes, H. Dupont Durst, Explosives detection using direct analysis in real time (DART) mass spectrometry, Propellants Explos Pyrotech. 35 (2010) 446-451.

[20] H. Wang, W. Sun, J. Zhang, X. Yang, T. Lin, L. Ding, Desorption corona beam ionization source for mass spectrometry, Analyst. 135 (2010) 688-695.

[21] R.M. Alberici, R.C. Simas, G.B. Sanvido, W. Romão, P.M. Lalli, M. Benassi, I.B.S. Cunha, M.N. Eberlin, Ambient mass spectrometry: Bringing MS into the "real world", Anal. Bioanal. Chem. 398 (2010) 265-294.

[22] F.M. Green, T.L. Salter, P. Stokes, I.S. Gilmore, O'Connorb G., Ambientmass spectrometry: Advances and applications in forensics, Surf. Interface Anal. 42 (2010) 347357.

[23] M.G. Blain, L.S. Riter, D. Cruz, D.E. Austin, G. Wu, W.R. Plass, R.G. Cooks, Towards the hand-held mass spectrometer: Design considerations, simulation, and fabrication of micrometer-scaled cylindrical ion traps, Int. J. Mass Spectrom. 236 (2004) 91-104.

[24] C.C. Mulligan, N. Talaty, R.G. Cooks, Desorption electrospray ionization with a portable mass spectrometer: In situ analysis of ambient surfaces, Chem. Commun. (2006) 17091711.

[25] N.L. Sanders, S. Kothari, G. Huang, G. Salazar, R.G. Cooks, Detection of explosives as negative ions directly from surfaces using a miniature mass spectrometer, Anal. Chem. 82 (2010) 5313-5316.

[26] J.M. Wells, M.J. Roth, A.D. Keil, J.W. Grossenbacher, D.R. Justes, G.E. Patterson, D.J. Barket Jr., Implementation of DART and DESI Ionization on a Fieldable Mass Spectrometer, J. Am. Soc. Mass Spectrom. 19 (2008) 1419-1424.

[27] E. Schramm, J. Hölzer, M. Pütz, R. Schulte-Ladbeck, R. Schultze, M. Sklorz, A. Ulrich, J. Wieser, R. Zimmermann, Real-time trace detection of security-relevant compounds in complex sample matrices by thermal desorption-single photon ionization-ion trap mass spectrometry (TD-SPI-ITMS) Spectrometry (TD-SPI-ITMS), Anal. Bioanal. Chem. 395 (2009) 1795-1807.

[28] M.R. Leahy-Hoppa, M.J. Fitch, R. Osiander, Terahertz spectroscopy techniques for explosives detection, Anal. Bioanal. Chem. 395 (2009) 247-257. 
[29] D.L. Woolard, E.R. Brown, M. Pepper, M. Kemp, Terahertz frequency sensing and imaging: A time of reckoning future applications?, Proc IEEE. 93 (2005) 1722-1743.

[30] H.-. Liu, H. Zhong, N. Karpowicz, Y. Chen, X.-. Zhang, Terahertz spectroscopy and imaging for defense and security applications, Proc IEEE. 95 (2007) 1514-1527.

[31] J.F. Federici, B. Schulkin, F. Huang, D. Gary, R. Barat, F. Oliveira, D. Zimdars, THz imaging and sensing for security applications - Explosives, weapons and drugs, Semicond Sci Technol. 20 (2005).

[32] H.-. Liu, Y. Chen, G.J. Bastiaans, X.-. Zhang, Detection and identification of explosive RDX by THz diffuse reflection spectroscopy, Opt. Express. 14 (2006) 415-423.

[33] J. Chen, Y. Chen, H. Zhao, G.J. Bastiaans, X.-. Zhang, Absorption coefficients of selected explosives and related compounds in the range of 0.1-2.8 THz, Opt. Express. 15 (2007) 12060-12067.

[34] M.R. Leahy-Hoppa, M.J. Fitch, X. Zheng, L.M. Hayden, R. Osiander, Wideband terahertz spectroscopy of explosives, Chem. Phys. Lett. 434 (2007) 227-230.

[35] T. Lo, I.S. Gregory, C. Baker, P.F. Taday, W.R. Tribe, M.C. Kemp, The very far-infrared spectra of energetic materials and possible confusion materials using terahertz pulsed spectroscopy, Vib. Spectrosc. 42 (2006) 243-248.

[36] O.M. Primera-Pedrozo, Y.M. Soto-Feliciano, L.C. Pacheco-Londoño, S.P. HernándezRivera, Detection of high explosives using reflection absorption infrared spectroscopy with fiber coupled grazing angle probe/FTIR, Sens. Imaging. 10 (2009) 1-13.

[37] Y. Mou, J.W. Rabalais, Detection and Identification of Explosive Particles in Fingerprints Using Attenuated Total Reflection-Fourier Transform Infrared Spectromicroscopy, J. Forensic Sci. 54 (2009) 846-850.

[38] J.L. Gottfried, F.C. De Lucia Jr., C.A. Munson, A.W. Miziolek, Laser-induced breakdown spectroscopy for detection of explosives residues: A review of recent advances, challenges, and future prospects, Anal. Bioanal. Chem. 395 (2009) 283-300.

[39] P. Lucena, A. Doña, L.M. Tobaria, J.J. Laserna, New challenges and insights in the detection and spectral identification of organic explosives by laser induced breakdown spectroscopy, Spectrochim. Acta Part B At. Spectrosc.

[40] F.C. De Lucia Jr., J.L. Gottfried, C.A. Munson, A.W. Miziolek, Double pulse laserinduced breakdown spectroscopy of explosives: Initial study towards improved discrimination, Spectrochim. Acta Part B At. Spectrosc. 62 (2007) 1399-1404.

[41] C. Bohling, K. Hohmann, D. Scheel, C. Bauer, W. Schippers, J. Burgmeier, U. Willer, G. Holl, W. Schade, All-fiber-coupled laser-induced breakdown spectroscopy sensor for hazardous materials analysis, Spectrochim. Acta Part B At. Spectrosc. 62 (2007) 1519-1527.

[42] Y. Dikmelik, C. McEnnis, J.B. Spicer, Femtosecond and nanosecond laser-induced breakdown spectroscopy of trinitrotoluene, Opt. Express. 16 (2008) 5332-5337.

[43] E.L. Izake, Forensic and homeland security applications of modern portable Raman spectroscopy, Forensic Sci. Int. 202 (2010) 1-8. 
[44] D.S. Moore, R.J. Scharff, Portable Raman explosives detection, Anal. Bioanal. Chem. 393 (2009) 1571-1578.

[45] L.C. Pacheco-Londoño, W. Ortiz-Rivera, O.M. Primera-Pedrozo, S.P. HernándezRivera, Vibrational spectroscopy standoff detection of explosives, Anal. Bioanal. Chem. 395 (2009) 323-335.

[46] A. Pettersson, I. Johansson, S. Wallin, M. Nordberg, H. Östmark, Near real-time standoff detection of explosives in a realistic outdoor environment at $55 \mathrm{~m}$ distance, Propellants Explos Pyrotech. 34 (2009) 297-306.

[47] Y. Fleger, L. Nagli, M. Gaft, M. Rosenbluh, Narrow gated Raman and luminescence of explosives, J Lumin. 129 (2009) 979-983.

[48] A. Portnov, I. Bar, S. Rosenwaks, Highly sensitive standoff detection of explosives via backward coherent anti-Stokes Raman scattering, Appl Phys B. 98 (2010) 529-535.

[49] E.M.A. Ali, H.G.M. Edwards, M.D. Hargreaves, I.J. Scowen, Detection of explosives on human nail using confocal Raman microscopy, J. Raman Spectrosc. 40 (2009) 144-149.

[50] E.M.A. Ali, H.G.M. Edwards, I.J. Scowen, In-situ detection of single particles of explosive on clothing with confocal Raman microscopy, Talanta. 78 (2009) 1201-1203.

[51] E.M.A. Ali, H.G.M. Edwards, I.J. Scowen, Raman spectroscopy and security applications: The detection of explosives and precursors on clothing, J. Raman Spectrosc. 40 (2009) 2009-2014.

[52] B.A. Paldus, A.A. Kachanov, An historical overview of cavity-enhanced methods, Can. J. Phys. 83 (2005) 975-999.

[53] G. Berden, R. Peeters, G. Meijer, Cavity ring-down spectroscopy: Experimental schemes and applications, Int. Rev. Phys. Chem. 19 (2000) 565-607.

[54] C. Ramos, P.J. Dagdigian, Detection of vapours of explosives and explosive-related compounds by ultraviolet cavity ringdown spectroscopy, Appl. Opt. 46 (2007) 620-627.

[55] C. Ramos, P.J. Dagdigian, Effect of photochemistry on molecular detection by cavity ringdown spectroscopy: Case study of an explosive-related compound, Appl. Opt. 46 (2007) 6526-6532.

[56] M. Snels, T. Venezia, L. Belfiore, Detection and identification of TNT, 2,4-DNT and 2,6DNT by near-infrared cavity ringdown spectroscopy, Chem. Phys. Lett. 489 (2010) 134-140.

[57] K.G. Furton, L.J. Myers, The scientific foundation and efficacy of the use of canines as chemical detectors for explosives, Talanta,. 54 (2001) 487-500.

[58] I. Gazit, J. Terkel, Explosives detection by sniffer dogs following strenuous physical activity, Applied Animal Behaviour Science,. 81 (2003) 149-161.

[59] J. Otto, M.F. Brown, W. Long III, Training rats to search and alert on contraband odors, Appl. Anim. Behav. Sci. 77 (2002) 217-232. 
[60] B. Marshall, C.G. Warr, M. de Bruyne, Detection of volatile indicators of illicit substances by the olfactory receptors of Drosophila melanogaster, Chem. Senses. 35 (2010) 613-625.

[61] R. Glatz, K. Bailey-Hill, Mimicking nature's noses: From receptor deorphaning to olfactory biosensing, Prog. Neurobiol. 93 (2011) 270-296.

[62] I. Gazit, A. Goldblatt, J. Terkel, Formation of an olfactory search image for explosives odours in sniffer dogs, Ethology. 111 (2005) 669-680.

[63] A. Lesniak, M. Walczak, T. Jezierski, M. Sacharczuk, M. Gawkowski, K. Jaszczak, Canine olfactory receptor gene polymorphism and its relation to odor detection performance by sniffer dogs, J. Hered. 99 (2008) 518-527.

[64] A. Corcelli, S. Lobasso, P. Lopalco, M. Dibattista, R. Araneda, Z. Peterlin, S. Firestein, Detection of explosives by olfactory sensory neurons, J. Hazard. Mater. 175 (2010) 10961100.

[65] J. Yinon, Detection of Explosives by Electronic Noses, Anal. Chem. 5 (2003).

[66] S.E. Stitzel, L.J. Cowen, K.J. Albert, D.R. Walt, Array-to-Array Transfer of an Artificial Nose, Anal. Chem. 73 (2001) 1307.

[67] M.E. Koscho, R.H. Grubbs, N.S. Lewis, Properties of vapor detector arrays formed through plasticization of carbon black-organic polymer composites., Anal. Chem. 74 (2002) 1307.

[68] H. Wohltjen, R. Dessy, Surface acoustic wave probe for chemical analysis. I, Introduction and instrument description, Anal. Chem. 51 (1979) 1458.

[69] C.F. Bernasconi, Kinetic and spectral study of some reactions of 2,4,6-trinitrotoluene in basic solution. I. Deprotonation and Janovsky complex formation, J. Org. Chem. 36 (1971) 1671.

[70] Y. Engel, R. Elnathan, A. Pevzner, G. Davidi, E. Flaxer, F. Patolsky, Supersensitive detection of explosives by silicon nanowire arrays, Angew. Chem. Int. Ed. 49 (2010) 68306835 .

[71] D. Gao, Z. Wang, B. Liu, L. Ni, M. Wu, Z. Zhang, Resonance energy transfer-amplifying fluorescence quenching at the surface of silica nanoparticles toward ultrasensitive detection of TNT, Anal. Chem. 80 (2008) 8545-8553.

[72] F. Wang, W. Wang, B. Liu, Z. Wang, Z. Zhang, Copolypeptide-doped polyaniline nanofibers for electrochemical detection of ultratrace trinitrotoluene, Talanta. 79 (2009) 376382.

[73] C.-- Yuan, C.-. Chang, Y.-. Hong, Y. Sung, Fabrication of MWNTs-PANI composite - a chemiresistive sensor material for the detection of explosive gases, Materials Science Poland. 27 (2009) 509.

[74] A.D. Aguilar, E.S. Forzani, M. Leright, F. Tsow, A. Cagan, R.A. Iglesias, L.A. Nagahara, I. Amlani, R. Tsui, N.J. Tao, A hybrid nanosensor for TNT vapor detection, Nano Lett. 10 (2010) 380-384. 
[75] S. Singh, Sensors-An effective approach for the detection of explosives, Journal of Hazardous Materials,. 144 (2007) 15-28.

[76] P. Rabenecker, K. Pinkwart, A look behind electrochemical detection of explosives, Propellants Explos Pyrotech. 34 (2009) 274-279.

[77] J. Wang, Electrochemical sensing of explosives, Electroanalysis. 19 (2007) 415-423.

[78] J. Wang, Analytical electrochemistry, 3rd ed., Wiley; John Wiley distributor, Hoboken, N.J.; Chichester, 2006.

[79] L. Agüí, D. Vega-Montenegro, P. Yáñez-Sedeño, J.M. Pingarrón, Rapid voltammetric determination of nitroaromatic explosives at electrochemically activated carbon-fibre electrodes, Anal.Bioanal.Chem. 382 (2005) 381-387.

[80] K. Cizek, C. Prior, C. Thammakhet, M. Galik, K. Linker, R. Tsui, A. Cagan, J. Wake, J.L. Belle, J. Wang, Integrated explosive preconcentrator and electrochemical detection system for 2,4,6-trinitrotoluene (TNT) vapor, Anal. Chim. Acta. 661 (2010) 117-121.

[81] G. Shi, Y. Qu, Y. Zhai, Y. Liu, Z. Sun, J. Yang, L. Jin, \{MSU/PDDA $\}_{n}$ LBL assembled modified sensor for electrochemical detection of ultratrace explosive nitroaromatic compounds, Electrochem. Commun. 9 (2007) 1719-1724.

[82] X.-. Fu, X. Chen, J. Wang, J.-. Liu, X.-. Huang, Amino functionalized mesoporous silica microspheres with perpendicularly aligned mesopore channels for electrochemical detection of trace 2,4,6-trinitrotoluene, Electrochim. Acta. 56 (2010) 102-107.

[83] J. Zang, C.X. Guo, F. Hu, L. Yu, C.M. Li, Electrochemical detection of ultratrace nitroaromatic explosives using ordered mesoporous carbon, Anal. Chim. Acta. 683 (2011) 187-191.

[84] D. Lu, A. Cagan, R.A.A. Munoz, T. Tangkuaram, J. Wang, Highly sensitive electrochemical detection of trace liquid peroxide explosives at a Prussian-blue 'artificialperoxidase' modified electrode, Analyst. 131 (2006) 1279-1281.

[85] S. Parajuli, W. Miao, Sensitive determination of hexamethylene triperoxide diamine explosives, using electrogenerated chemiluminescence enhanced by silver nitrate, Anal. Chem. 81 (2009) 5267-5272.

[86] J. Wang, M. Pumera, Microchip flow-injection analysis of trace 2,4,6-trinitrotoluene (TNT) using mercury-amalgam electrochemical detector, Talanta,. 69 (2006) 984-987.

[87] M.-. Chuang, J.R. Windmiller, P. Santhosh, G.V. Ramírez, M. Galik, T.-. Chou, J. Wang, Textile-based Electrochemical Sensing: Effect of Fabric Substrate and Detection of Nitroaromatic Explosives, Electroanalysis. 22 (2010) 2511-2518.

[88] J.-. Chen, J.-. Shih, C.-. Liu, M.-. Kuo, J.-. Zen, Disposable electrochemical sensor for determination of nitroaromatic compounds by a single-run approach, Anal. Chem. 78 (2006) $3752-3757$.

[89] V. Bhalla, X. Zhao, V. Zazubovich, Detection of explosive compounds using Photosystem II-based biosensor, J Electroanal Chem. 657 (2011) 84-90. 
[90] L. Yu, Y. Huang, X. Jin, A.J. Mason, X. Zeng, Ionic liquid thin layer EQCM explosives sensor, Sens Actuators, B Chem. 140 (2009) 363-370.

[91] R.G. Smith, N. D'Souza, S. Nicklin, A review of biosensors and biologically-inspired systems for explosives detection, Analyst. 133 (2008) 571-584.

[92] G.P. Anderson, S.C. Moreira, P.T. Charles, I.L. Medintz, E.R. Goldman, M. Zeinali, C.R. Taitt, TNT detection using multiplexed liquid array displacement immunoassays, Anal. Chem. 78 (2006) 2279-2285.

[93] G.P. Anderson, M. Moore, P.T. Charles, E.R. Goldman, Bead-based fluid array detection of pentaerythritol tetranitrate: Comparison of monoclonal vs. Ilama polyclonal antibodies, Anal. Lett. 43 (2010) 2913-2922.

[94] K. Nagatomo, T. Kawaguchi, N. Miura, K. Toko, K. Matsumoto, Development of a sensitive surface plasmon resonance immunosensor for detection of 2,4-dinitrotoluene with a novel oligo (ethylene glycol)-based sensor surface, Talanta. 79 (2009) 1142-1148.

[95] P. Singh, T. Onodera, Y. Mizuta, K. Matsumoto, N. Miura, K. Toko, Dendrimer modified biochip for detection of 2,4,6 trinitrotoluene on SPR immunosensor: Fabrication and advantages, Sens Actuators, B Chem. 137 (2009) 403-409.

[96] M.S. Meaney, V.L. McGuffin, Luminescence-based methods for sensing and detection of explosives, Anal. Bioanal. Chem. 391 (2008) 2557-2576.

[97] S.J. Toal, J.C. Sanchez, R.E. Dugan, W.C. Trogler, Visual detection of trace nitroaromatic explosive residue using photoluminescent metallole-containing polymers, J. Forensic Sci. 52 (2007) 79-83.

[98] J.C. Sanchez, S.J. Toal, Z. Wang, R.E. Dugan, W.C. Trogler, Selective detection of trace nitroaromatic, nitramine, and nitrate ester explosive residues using a three-step fluorimetric sensing process: A tandem turn-off, turn-on sensor, J. Forensic Sci. 52 (2007) 1308-1313.

[99] J.C. Sanchez, A.G. DiPasquale, A.L. Rheingold, W.C. Trogler, Synthesis, luminescence properties, and explosives sensing with 1,1-tetraphenylsilole- and 1,1-silafluorene-vinylene polymers, Chem. Mater. 19 (2007) 6459-6470.

[100] J.C. Sanchez, W.C. Trogler, Efficient blue-emitting silafluorene-fluorene-conjugated copolymers: Selective turn-off/turn-on detection of explosives, J. Mater. Chem. 18 (2008) 3143-3156.

[101] H. Du, G. He, T. Liu, L. Ding, Y. Fang, Preparation of pyrene-functionalized fluorescent film with a benzene ring in spacer and sensitive detection to picric acid in aqueous phase, $\mathrm{J}$. Photochem. Photobiol. A. 217 (2011) 356-362.

[102] G.H. Shi, Z.B. Shang, Y. Wang, W.J. Jin, T.C. Zhang, Fluorescence quenching of CdSe quantum dots by nitroaromatic explosives and their relative compounds, Spectrochim. Acta Part A Mol. Biomol. Spectrosc. 70 (2008) 247-252.

[103] M. Algarra, B.B. Campos, M.S. Miranda, J.C.G.E. da Silva, CdSe quantum dots capped PAMAM dendrimer nanocomposites for sensing nitroaromatic compounds, Talanta. 
[104] M.P.P. Monterola, B.W. Smith, N. Omenetto, J.D. Winefordner, Photofragmentation of nitro-based explosives with chemiluminescence detection, Anal. Bioanal. Chem. 391 (2008) 2617-2626.

[105] A. Ponnu, E.V. Anslyn, A fluorescence-based cyclodextrin sensor to detect nitroaromatic explosives, Supramol. Chem. 22 (2010) 65-71.

[106] T. Caron, M. Guillemot, P. Montméat, F. Veignal, F. Perraut, P. Prené, F. SereinSpirau, Ultra trace detection of explosives in air: Development of a portable fluorescent detector, Talanta. 81 (2010) 543-548.

[107] T. Caron, S. Clavaguera, M. Huron, P. Montméat, E. Pasquinet, J.-. Lère-Porte, F. Serein-Spirau, F. Perraut, P. Prené, Detection of explosive vapors: Development and performances of a fluorescence sensor, Chem. Eng. Trans. 23 (2010) 25-30.

[108] M.D. Woodka, V.P. Schnee, M.P. Polcha, Fluorescent polymer sensor array for detection and discrimination of explosives in water, Anal. Chem. 82 (2010) 9917-9924.

[109] A. McCluskey, C.I. Holdsworth, M.C. Bowyer, Molecularly imprinted polymers (MIPs): Sensing, an explosive new opportunity?, Org. Biomol. Chem. 5 (2007) 3233-3244.

[110] I. Chianella, S.A. Piletsky, K. Karim, E.V. Piletska, A. Guerreiro, M. Romero Guerra, A.P.F. and Turner, Molecularly imprinted polymers as materials for crime prevention and detection (2004).

[111] P.D. Schwartz, G.M. Murray, O.M. Uy, B.Q. Le, D.D. Stott, A.L. Lew, S.X. Ling, J.J. Suter, Apparatus and methods for detecting explosives and other substances.

PCT/US2001/014190.

[112] G. Bunte, J. Hürttlen, H. Pontius, K. Hartlieb, H. Krause, Gas phase detection of explosives such as 2,4,6-trinitrotoluene by molecularly imprinted polymers, Anal. Chim. Acta. 591 (2007) 49-56.

[113] G. Bunte, M. Heil, D. Rüseling, J. Hürttlen, H. Pontius, H. Krause, Trace detection of explosives vapours by molecularly imprinted polymers for security measures, Propellants Explos Pyrotech. 34 (2009) 245-251.

[114] D. Roeseling, T. Tuercke, H. Krause, S. Loebbecke, Microreactor-based synthesis of molecularly imprinted polymer beads used for explosive detection, Org. Process Res. Dev. 13 (2009) 1007-1013.

[115] R.C. Stringer, S. Gangopadhyay, S.A. Grant, Detection of nitroaromatic explosives using a fluorescent-labeled imprinted polymer, Anal. Chem. 82 (2010) 4015-4019.

[116] S.W. Thomas III, G.D. Joly, T.M. Swager, Chemical sensors based on amplifying fluorescent conjugated polymers, Chem. Rev. 107 (2007) 1339-1386.

[117] D. Nie, D. Jiang, D. Zhang, Y. Liang, Y. Xue, T. Zhou, L. Jin, G. Shi, Two-dimensional molecular imprinting approach for the electrochemical detection of trinitrotoluene, Sensors Actuators B: Chem. 156 (2011) 43-49.

[118] R. Saito, Physical properties of carbon nanotubes, Imperial College Press, London, 1998. 
[119] J. Wang, S.B. Hocevar, B. Ogorevc, Carbon nanotube-modified glassy carbon electrode for adsorptive stripping voltammetric detection of ultratrace levels of 2,4,6trinitrotoluene, Electrochemistry Communications. 6 (2004) 176-179.

[120] P.-. Chen, S. Sukcharoenchoke, K. Ryu, L.G. De Arco, A. Badmaev, C. Wang, C. Zhou, 2,4,6-Trinitrotoluene (TNT) chemical sensing based on aligned single-walled carbon nanotubes and ZnO nanowires, Adv Mater. 22 (2010) 1900-1904.

[121] M. Park, L.N. Cella, W. Chen, N.V. Myung, A. Mulchandani, Carbon nanotubes-based chemiresistive immunosensor for small molecules: Detection of nitroaromatic explosives, Biosens. Bioelectron.

[122] R. Schulte-Ladbeck, M. Vogel, U. Karst, Recent methods for the determination of peroxide-based explosives, Analytical and Bioanalytical Chemistry. 386 (2006) 559-565.

[123] S. Banerjee, S.K. Mohapatra, M. Misra, I.B. Mishra, The detection of improvised nonmilitary peroxide based explosives using a titania nanotube array sensor, Nanotechnology. 20 (2009).

[124] S. Hrapovic, E. Majid, Y. Liu, K. Male, J.H.T. Luong, Metallic nanoparticle-carbon nanotube composites for electrochemical determination of explosive nitroaromatic compounds, Anal. Chem. 78 (2006) 5504-5512.

[125] H. Yang, C. Shan, F. Li, D. Han, Q. Zhang, L. Niu, Covalent functionalization of polydisperse chemically-converted graphene sheets with amine-terminated ionic liquid, Chem. Commun. (2009) 3880-3882.

[126] S. Guo, D. Wen, Y. Zhai, S. Dong, E. Wang, lonic liquid-graphene hybrid nanosheets as an enhanced material for electrochemical determination of trinitrotoluene, Biosensors and Bioelectronics. 26 (2011) 3475-3481.

[127] Y. Jiang, H. Zhao, N. Zhu, Y. Lin, P. Yu, L. Mao, A simple assay for direct colorimetric visualization of trinitrotoluene at picomolar levels using gold nanoparticles, Angew. Chem. Int. Ed. 47 (2008) 8601-8604.

[128] S.S.R. Dasary, A.K. Singh, D. Senapati, H. Yu, P.C. Ray, Gold nanoparticle based label-free SERS probe for ultrasensitive and selective detection of trinitrotoluene, J. Am. Chem. Soc. 131 (2009) 13806-13812.

[129] L. Yang, L. Ma, G. Chen, J. Liu, Z.-. Tian, Ultrasensitive SERS detection of TNT by imprinting molecular recognition using a new type of stable substrate, Chem. Eur. J. 16 (2010) 12683-12693.

[130] S. Chang, H. Ko, S. Singamaneni, R. Gunawidjaja, V.V. Tsukruk, Nanoporous membranes with mixed nanoclusters for Raman-based label-free monitoring of peroxide compounds, Anal. Chem. 81 (2009) 5740-5748.

[131] X. Liu, L. Zhao, H. Shen, H. Xu, L. Lu, Ordered gold nanoparticle arrays as surfaceenhanced Raman spectroscopy substrates for label-free detection of nitroexplosives, Talanta. 83 (2011) 1023-1029.

[132] X. Fang, S.R. Ahmad, Detection of explosive vapour using surface-enhanced Raman spectroscopy, Appl Phys B. 97 (2009) 723-726. 
[133] H. Wackerbarth, C. Salb, L. Gundrum, M. Niederkrüger, K. Christou, V. Beushausen, W. Viöl, Detection of explosives based on surface-enhanced Raman spectroscopy, Appl. Opt. 49 (2010) 4362-4366.

[134] H. Wackerbarth, L. Gundrum, C. Salb, K. Christou, W. Viöl, Challenge of false alarms in nitroaromatic explosive detection-a detection device based on surface-enhanced Raman spectroscopy, Appl. Opt. 49 (2010) 4367-4371.

[135] M. Riskin, R. Tel-Vered, I. Willner, Imprinted au-nanoparticle composites for the ultrasensitive surface plasmon resonance detection of hexahydro-1,3,5-trinitro-1,3,5-triazine (RDX), Adv Mater. 22 (2010) 1387-1391.

[136] T. Kawaguchi, D.R. Shankaran, S.J. Kim, K. Matsumoto, K. Toko, N. Miura, Surface plasmon resonance immunosensor using Au nanoparticle for detection of TNT, Sens Actuators, B Chem. 133 (2008) 467-472.

[137] J. Wang, G. Liu, H. Wu, Y. Lin, Sensitive electrochemical immunoassay for 2,4,6trinitrotoluene based on functionalized silica nanoparticle labels, Anal. Chim. Acta. 610 (2008) 112-118.

[138] W. Chen, N.B. Zuckerman, J.P. Konopelski, S. Chen, Pyrene-functionalized ruthenium nanoparticles as effective chemosensors for nitroaromatic derivatives, Anal. Chem. 82 (2010) 461-465.

[139] K.A. Marx, Quartz crystal microbalance: A useful tool for studying thin polymer films and complex biomolecular systems at the solution - Surface interface, Biomacromolecules. 4 (2003) 1099-1120.

[140] A. Larsson, J. Angbrant, J. Ekeroth, P. Månsson, B. Liedberg, A novel biochip technology for detection of explosives - TNT: Synthesis, characterisation and application, Sens Actuators, B Chem. 113 (2006) 730-748.

[141] M. Cerruti, J. Jaworski, D. Raorane, C. Zueger, J. Varadarajan, C. Carraro, S.-. Lee, R. Maboudian, A. Majumdar, Polymer-oligopeptide composite coating for selective detection of explosives in water, Anal. Chem. 81 (2009) 4192-4199.

[142] D. Lubczyk, C. Siering, J. Lörgen, Z.B. Shifrina, K. Müllen, S.R. Waldvogel, Simple and sensitive online detection of triacetone triperoxide explosive, Sensors Actuators B: Chem. In Press, Corrected Proof.

[143] W.E. Tenhaeff, L.D. Mcintosh, K.K. Gleason, Synthesis of poly(4-vinylpyridine) thin films by initiated chemical vapor deposition (icvd) for selective nanotrench-based sensing of nitroaromatics, Adv. Funct. Mater. 20 (2010) 1144-1151.

[144] Y. Long, H. Chen, Y. Yang, H. Wang, Y. Yang, N. Li, K. Li, J. Pei, F. Liu, Electrospun nanofibrous film doped with a conjugated polymer for DNT fluorescence sensor, Macromolecules. 42 (2009) 6501-6509.

[145] J.P. Lock, E. Geraghty, L.C. Kagumba, K.K. Mahmud, Trace detection of peroxides using a microcantilever detector, Thin Solid Films. 517 (2009) 3584-3587. 
Figure 1

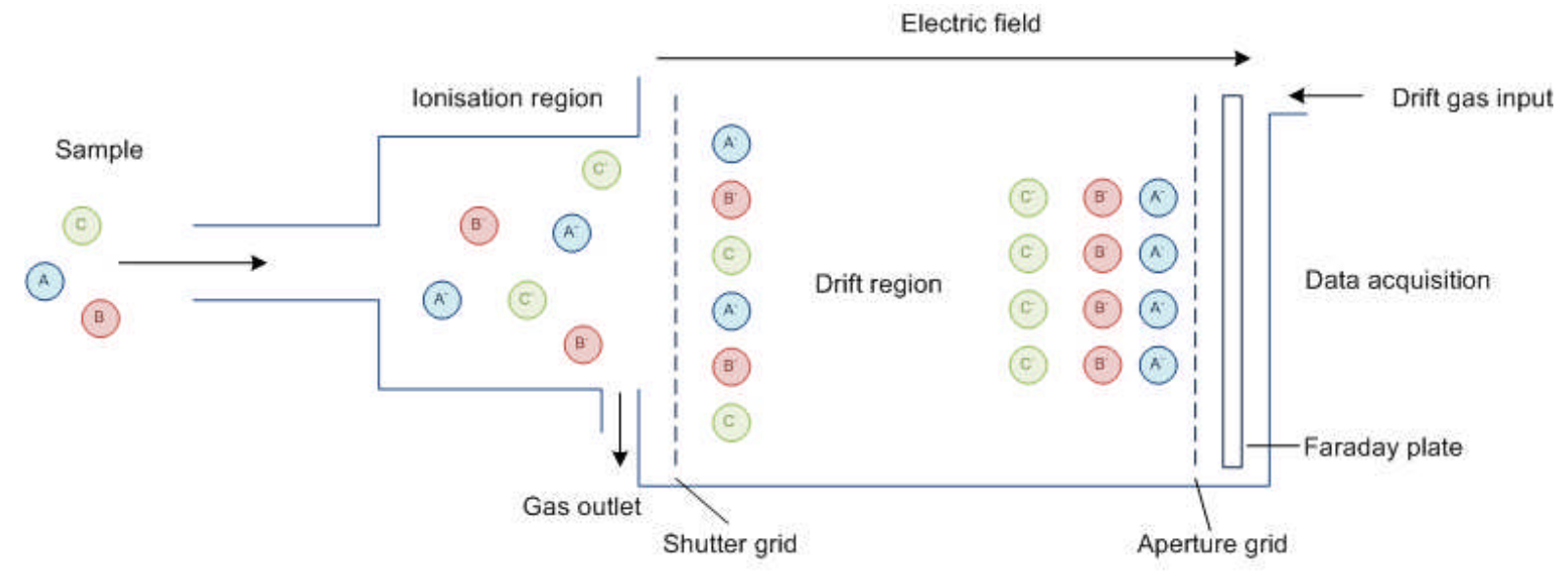


Figure 2

External

cavity diode

laser
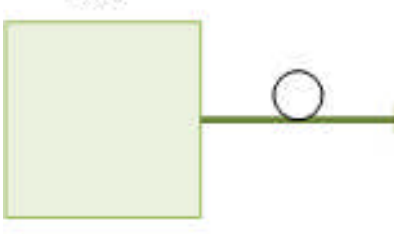

Waverneter

Photodiode
Acousto-optic switch
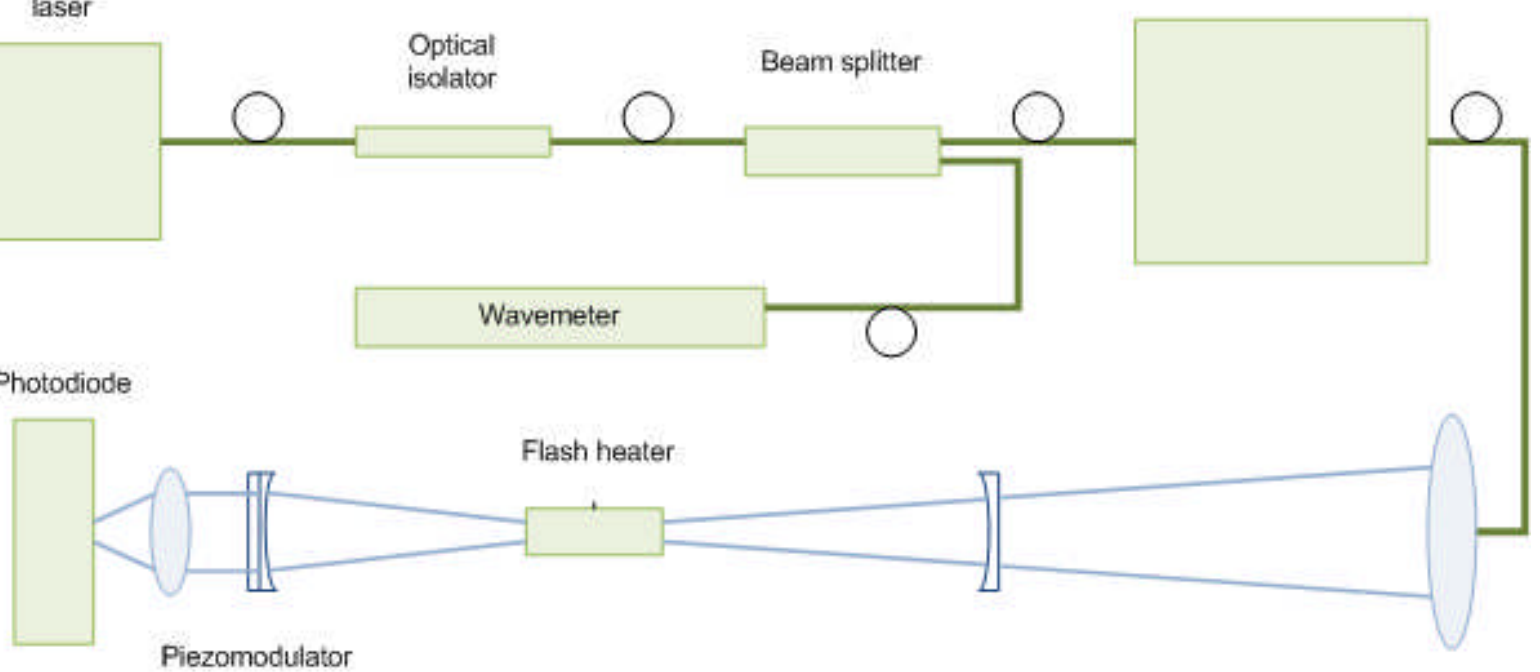

Collimating lens 
Figure 3

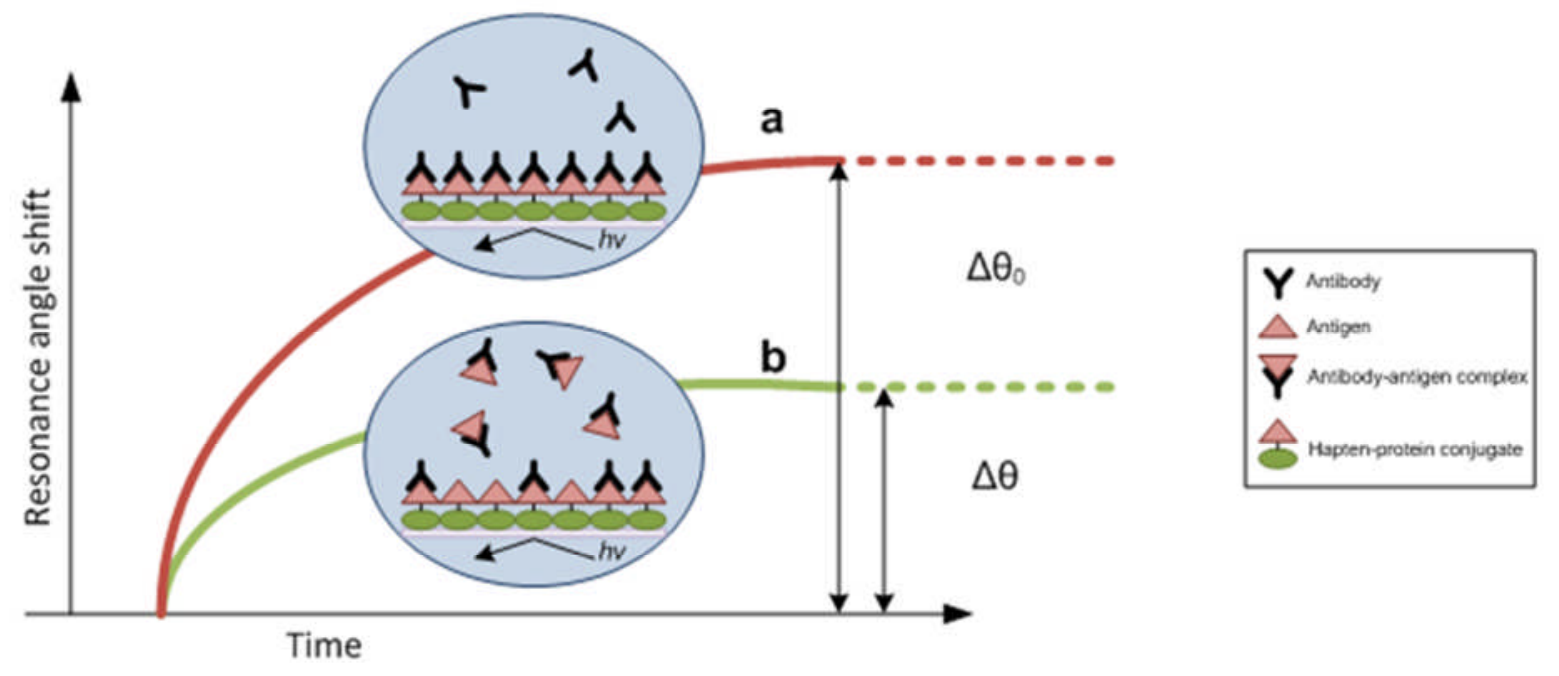


Figure 4

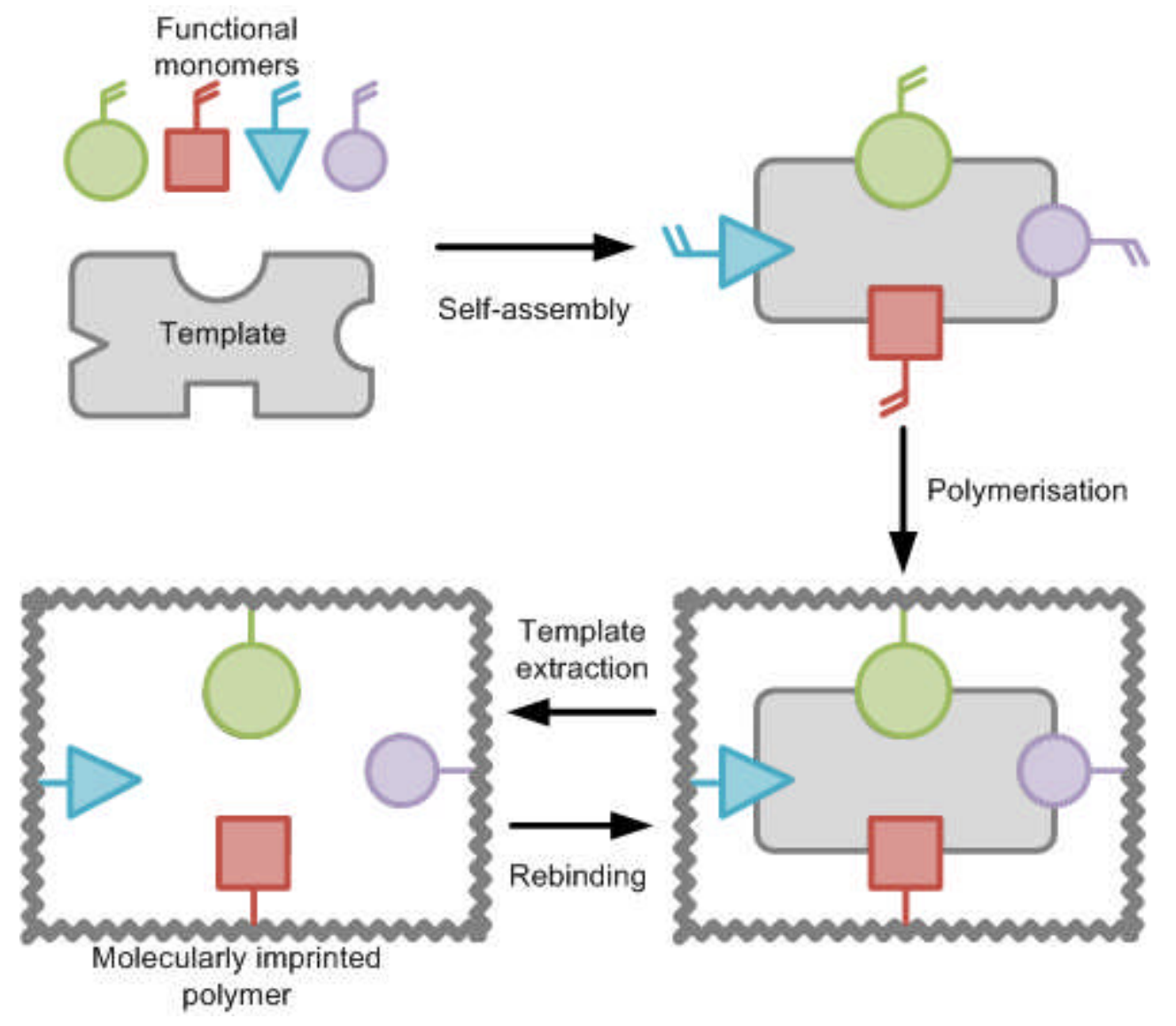

